\title{
Sensitivity of phytoplankton distributions to vertical mixing along a North Atlantic transect
}

\author{
L. Hahn-Woernle ${ }^{1}$, H. A. Dijkstra ${ }^{1}$, and H. J. Van der Woerd ${ }^{2}$ \\ ${ }^{1}$ Institute for Marine and Atmospheric Research Utrecht (IMAU), Dept. of Physics and Astronomy, Utrecht University, \\ P.O. Box 80.005, 3508 TA Utrecht, the Netherlands \\ ${ }^{2}$ Institute for Environmental Studies (IVM), Free University of Amsterdam, the Netherlands \\ Correspondence to: L. Hahn-Woernle (1.hahn-woernle@uu.nl)
}

Received: 31 January 2014 - Published in Ocean Sci. Discuss.: 14 March 2014

Revised: 23 October 2014 - Accepted: 11 November 2014 - Published: 11 December 2014

\begin{abstract}
Using in situ data of upper ocean vertical mixing along a transect in the North Atlantic and a one-dimensional phytoplankton growth model, we study the sensitivity of the surface phytoplankton concentration to vertical mixing distributions. The study is divided into two parts. In the first part, the model is calibrated to the observations. The optical model parameters are determined from measurements of the light attenuation. The biological parameters are calibrated to three different reference stations with observed vertical profiles of the chlorophyll $a(\mathrm{Chl} a)$ concentration and the nutrient concentration. In the second part, the sensitivity of the three model calibrations to the vertical mixing is studied. Therefore measured vertical mixing profiles are applied to the model. These mixing profiles are based on the measurements along the transect and are treated as a set of possible mixing situations of the North Atlantic. Results show that shifts in vertical mixing are able to induce a transition from an upper chlorophyll maximum to a deep one and vice versa. Furthermore, a clear correlation between the surface phytoplankton concentration and the mixing induced nutrient flux is found for nutrient-limited cases. This may open up the possibility to extract characteristics of vertical mixing from satellite ocean colour data using data-assimilation methods.
\end{abstract}

\section{Introduction}

Thanks to long-term in situ and satellite observations of ocean surface chlorophyll $a$ (Chl $a$ ) concentrations, the plankton variability can be studied on timescales longer than seasonal. On interannual-to-decadal timescales, Chl $a$ concentrations show changes that correlate well to variations in climate indices such as the North Atlantic Oscillation (Martinez et al., 2009). Long-term trends in Chl $a$ were presented in Boyce et al. (2010) based on a century long database of in situ Chl $a$ and ocean transparency measurements. Although the results are under debate, it is clear that long-term trends in Chl $a$ are non-uniform over the globe and well correlated to the increase in sea surface temperature (SST). For the North Atlantic (north of $20^{\circ} \mathrm{N}$ ), Wernand et al. (2013) found an average rate of increase of about $0.0071 \mathrm{mg} \mathrm{m}^{-3} \mathrm{yr}^{-1}$ over the last century. On a shorter timescale (decades), however, much larger local variations are observed (Antoine et al., 2005).

The most significant feature of the local Chl $a$ variations is a phytoplankton bloom. Although the actual cause for the bloom is still not clarified, most of the theories consider vertical mixing as a key factor in its onset (Sverdrup, 1953; Behrenfeld et al., 2006). The growth progression is described as follows: during winter, the deep mixing brings nutrients into the euphotic layer. Simultaneously, the deep mixing distributes the phytoplankton over the euphotic layer and below, reducing the total exposure to photosynthetically active radiation (PAR). During spring, the shallowing of the mixed layer (ML) exposes the phytoplankton to more PAR. This enhances growth at the surface and leads to an upper chlorophyll maximum (UCM) given that enough nutrients are available (Behrenfeld, 2010; Lozier et al., 2011). Since PAR is absorbed by the phytoplankton, less of it reaches below the UCM where growth becomes light limited. The shallowing of the mixed layer also reduces the nutrient entrainment into 
the euphotic layer. As the warm season proceeds the necessary nutrients (e.g. phosphorus and nitrogen) become depleted in the ML, resulting in less phytoplankton growth at the surface. Consequently, PAR can again penetrate below the ML to the nutrient richer water. The dominant phytoplankton growth is shifted below the ML. A so-called deep chlorophyll maximum (DCM) is formed. The DCM is the most dominant appearance of phytoplankton in strongly stratified regions such as the subtropical North Atlantic.

Since stratification is strongly connected to the SST, climate warming could have a strong influence on the Chl $a$ concentration. Qualitative mechanisms aiming to explain the consequences for $\mathrm{Chl} a$ concentrations due to climate warming have, for example, been suggested by Doney (2006). In areas where phytoplankton is nutrient limited, e.g. in the midlatitude Atlantic, an increase in SST will inhibit vertical mixing and lead to stratification. In a warming ocean the transport of nutrients into the upper ocean is hence expected to decrease. In areas where the phytoplankton is light limited, such as in the northern North Atlantic, a SST increase will reduce the depth of the ML (MLD) and hence one would expect an increase in phytoplankton. The fact that this trend is not observed in high-latitude regions according to data in Boyce et al. (2010) indicates that vertical mixing processes are not solely controlled by stratification. Indeed, it is known from basic upper-ocean turbulence measurements and theory that, apart from the surface buoyancy forcing, vertical mixing is also strongly dependent on the surface wind-stress forcing. In addition, the background stratification can also be substantially affected by advection of heat and salt due to ocean currents, and in particular by the presence of meso-scale eddies (McGillicuddy et al., 2007).

In order to understand the Chl $a$ patterns at the surface, the turbulent processes controlling the upper ocean need to be understood. The mixing coefficient $K_{T}\left[\mathrm{~m}^{2} \mathrm{~s}^{-1}\right]$ is a measure for the vertical mixing of heat and salt. At any particular location in the open ocean, the vertical profile of $K_{T}$ is determined by the background stratification (or buoyancy frequency $N$ ), the turbulent kinetic energy dissipation rate $\varepsilon$ and a mixing efficiency (Jurado et al., 2012b). Over the last decade, microstructure turbulence measurements of the upper ocean have been carried out along a few sections in the Atlantic Ocean, see Roget et al. (2006) for an overview. Using a microstructure profiler, the distribution of $K_{T}$ along a south-north transect in the eastern North Atlantic during the STRATIPHYT-I cruise in July-August 2009 and the STRATIPHYT-II cruise in April-May 2011 was determined (Jurado et al., 2012a, b). The averaged station profiles of $K_{T}$ along this section clearly indicate high values in the upper ML and a decrease near its base. At some locations the profiles of $K_{T}$ slightly increase below the ML before background values of $10^{-5}-10^{-4} \mathrm{~m}^{2} \mathrm{~s}^{-1}$ are approached at about $100 \mathrm{~m}$ depth. Satellite ocean colour observations (MODIS-AQUA) of August 2009 indicate a meridional gradient in $\mathrm{Chl} a$ with values increasing northward. The combined observations support the correlation between stratification and growth: while the stratification leads to a nutrient limitation in the ML in the south, it enhances growth in the ML due to higher PAR availability in the north. In spring 2011, satellite ocean colour observations are characterised by a high concentration around $45^{\circ} \mathrm{N}$ and decreasing Chl $a$ concentrations north and south of this. In situ vertical mixing profiles of $K_{T}$ indicate that the water column is stratified up to about $45^{\circ} \mathrm{N}$. Further north the water column is almost homogeneously mixed down to $100 \mathrm{~m}$ depth (Jurado et al., 2012a, b). The low Chl $a$ concentrations in the north follow thus from light limitation.

The effect of vertical mixing on phytoplankton distributions is difficult to monitor in the ocean and it is common to do laboratory experiments and use ocean-phytoplankton models (Ryabov et al., 2010; Klausmeier and Litchman, 2001; Beckmann and Hense, 2007). The results in Huisman et al. (2006) show that the state of the phytoplankton profile is strongly dependent on the strength of the vertical mixing. Ryabov et al. (2010) studied the effect of stratification on the model state and forced the system into DCM and UCM states by changing the strength of the vertical mixing. These models, however, contain a number of uncertain parameters both in the turbulence model and in the plankton model.

Many experiments and measurements are made to determine for example the growth rate of individual phytoplankton species under certain environmental conditions (Peters et al., 2006). Results show that growth rates do not only vary between species but also due to environmental changes. Alternatively, parameter values can be "tuned" to observations at one particular well-observed location and the response of the model at other locations to a different surface forcing is studied under the assumption that the tuned parameters do not change (Omta et al., 2009). Only in very special circumstances is a vertical profile of the mixing coefficient $K_{T}$ available for verification of the quality of the turbulence model used (Johnk et al., 2008).

This work is motivated by the availability of an observed integral picture (forcing, mixing, nutrients, phytoplankton, optical properties) over the eastern North Atlantic during summer 2009 and spring 2011 from the STRATIPHYT cruises. Using ocean-plankton models and data-assimilation methods we eventually aim to tackle an ambitious inverse problem: given the meteorological surface forcing, can we estimate the vertical mixing coefficient $K_{T}$ of the upper ocean based on satellite-derived ocean colour data? The sensitivity of the phytoplankton growth to changes in vertical mixing plays a key role in this problem, even more so when trying to reproduce it in a model. As a first step, we study here the effect of different vertical mixing profiles on the modelled surface phytoplankton concentration. Thereto we use the advection-reaction-diffusion phytoplankton model by Ryabov et al. (2010), which we calibrate to the in situ measurements of three STRATIPHYT stations. To study the effect of the vertical mixing on the phytoplankton growth, 
the three model calibrations are run under different mixing conditions. These conditions are based on the $K_{T}$ measurements of the STRATIPHYT cruises and are treated as a representative set of vertical mixing situations common for the North Atlantic. The calibration of model parameters to a specific location in the North Atlantic and the subsequent use of measured vertical mixing profiles for the calibrated model distinguishes this work from previous sensitivity studies. The aim is to improve the understanding of the effect of smallscale variances in the vertical mixing on the phytoplankton growth.

The paper is structured as follows. In Sect. 2, the relevant satellite data and the measurements of the STRATIPHYT cruises are presented. Next, in Sect. 3, the phytoplankton model is presented and its calibration (e.g. parameter tuning) is discussed in Sect. 4. The main analysis of the sensitivity of the equilibrium phytoplankton distributions to the vertical mixing profiles is presented in Sect. 5. Finally, in Sect. 6 the results are discussed and conclusions are formulated.

\section{Data}

For the analysis presented in this paper, we use both satellite colour data as well as in situ data measured during the STRATIPHYT cruises. Additional information on the data can be obtained from http://oceancolor.gsfc.nasa.gov and http://projects.nioz.nl/stratiphyt, respectively.

\subsection{Satellite data}

During the past decades the range of applications for satellite data and their reliability has improved significantly. An important application is the measurement of Chl $a$ surface concentration which can be used as a measure for the phytoplankton concentration close to the ocean surface. The data are based on the reflectance of blue and green wavelengths and can therefore only be obtained for the first metres of the water column. Figure $1 \mathrm{~b}$ shows $1^{\circ} \times 1^{\circ}$ box averaged and monthly mean values of the $\mathrm{Chl} a$ surface concentration recorded by the MODIS on the Aqua satellite. To retrieve the Chl $a$ concentrations from MODIS Aqua ocean colour data, the OC3M algorithm (O'Reilly et al., 2000) is used. The data are plotted along the ship track in the North Atlantic during the STRATIPHYT cruises (shown in Fig. 1a) over the years 2009 to 2011. Black data points correspond to gaps in the data, e.g. due to high cloud coverage or the lack of sunlight.

The daily mean Aqua MODIS PAR data is used in the model to determine the intensity of the incoming PAR at each station. In situ data would have been also available, but would have been too sparse and variable to determine the mean incoming PAR over an entire day. In order to facilitate the reading, the term light is used instead of PAR when dealing with the model.
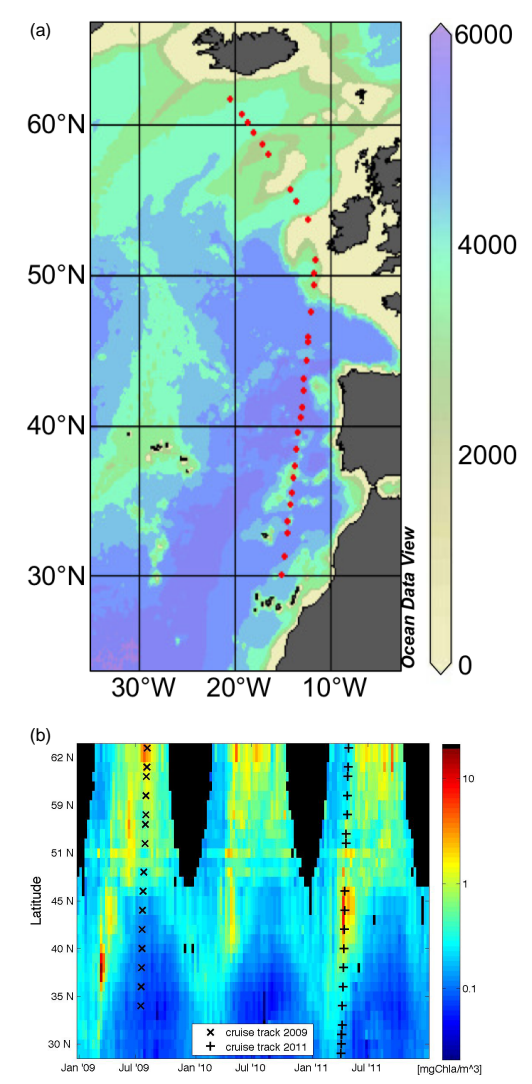

Figure 1. (a) Bathymetry of the North Atlantic with the track of the STRATIPHYT cruises. The colours show the water depth in metres. (b) MODIS Aqua chlorophyll $a$ surface concentration plotted along the track in (a). The black crosses and pluses indicate measurement stations during the STRATIPHYT cruises in summer 2009 and spring 2011, respectively.

\subsection{In situ data}

During the two STRATIPHYT cruises in summer 2009 and spring 2011 the ship stopped at one latitudinal station per day to measure several depth profiles. Though these measurements give only snapshots into the vertical structure of the North Atlantic, there is evidence (Jurado et al., 2012b) that they are a good representation of the seasonal characteristics. We refer to the data sets of the 2009 and 2011 cruises as summer data and spring data, respectively.

The obtained temperature microstructure measurements were used to derive depth profiles for the vertical mixing coefficient $K_{T}$ according to the Osborn and Cox model (Osborn, 1972). $K_{T}$ was computed from the temperature variance dissipation rate, $\chi_{T}$, according to

$K_{T}=\frac{\chi_{T}}{2}\left(\frac{\partial \bar{T}}{\partial z}\right)^{-2} \quad ; \quad \chi_{T}=6 D_{T} \overline{\left(\frac{\partial T^{\prime}}{\partial z}\right)^{2}}$,

where $D_{T}$ is the molecular diffusivity of heat $\left(\approx 1.4 \times 10^{-7} \mathrm{~m}^{2} \mathrm{~s}^{-1}\right)$. The overbar indicates a 

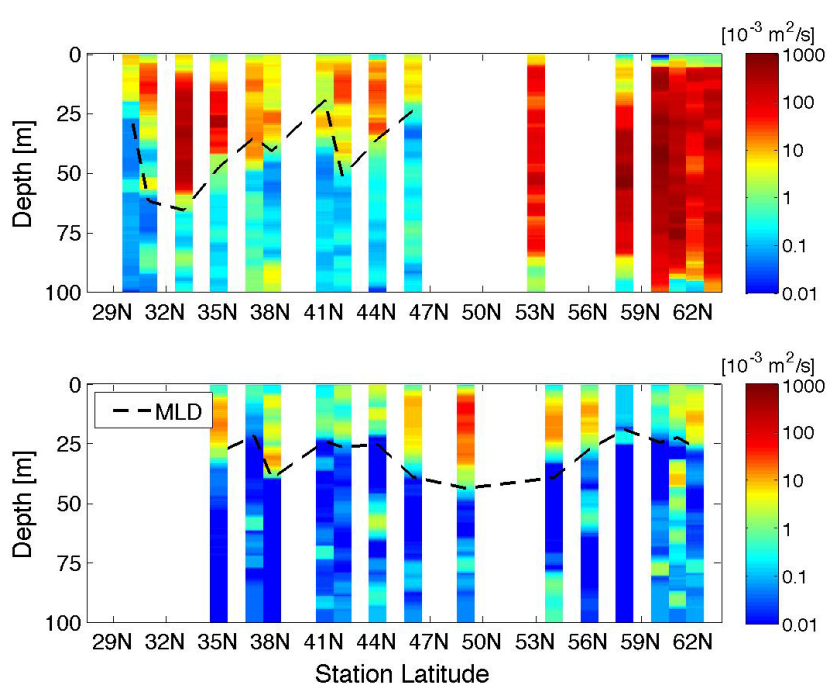

Figure 2. Interpolated and smoothed vertical mixing coefficient in spring (top) and summer (bottom) along the transect in Fig. 1a. The dashed curve indicates the MLD.

trimmed-smoothed-sharpened-filtered and depth-binned quantity and $T^{\prime}$ is the temperature fluctuation part (for details see Jurado et al., 2012b).

In Fig. 2 the station-mean, smoothed and interpolated profiles for $K_{T}$ are shown for both cruises (Jurado et al., 2012a, b). Here, the profiles are smoothed over windows of $5 \mathrm{~m}$ depth to guarantee the compatibility with the numerical scheme used in the phytoplankton model, as will be explained below. The MLD is defined as the depth at which the temperature difference with respect to the surface is $0.5^{\circ} \mathrm{C}$ (Levitus et al., 2000). In spring, the MLD ranges between 20 and $60 \mathrm{~m}$ for stratified stations up to $46^{\circ} \mathrm{N}$. Further north, the water column is nearly homogeneously mixed. In summer, the profiles of the mixing coefficient show stratified characteristics for all stations with maximum values of the MLD around $45 \mathrm{~m}$. The strength of the vertical mixing and its vertical properties change both seasonally as well as latitudinally.

For the model implementation, missing data points within the vertical profile were linearly interpolated and profiles were smoothed over windows of $10 \mathrm{~m}$ depth. This is done to guarantee the compatibility with the diffusion scheme used in the phytoplankton model.

Figure 3 shows the phytoplankton concentration measured during the spring and the summer cruise, respectively. The profiles were derived from CTD fluorescence measurements in units of the Chelsea Aqua $3 \mathrm{Chl} a$ concentration $\left[\mathrm{g} \mathrm{L}^{-1}\right.$ ] (Suggett et al., 2011). For the model the data needed to be converted from Chl $a$ to cells. The ratio of Chl $a$ per cell can vary significantly depending on species and environmental conditions. Up to now there is no universal equation explaining this complex relation (Falkowski and Raven, 2007). Therefore a general ratio of $0.2 \times 10^{9}$ cells $(\mu \mathrm{g} \mathrm{Chl} a)^{-1}$ is chosen for simplicity. This ratio is based on the cell : nutrient
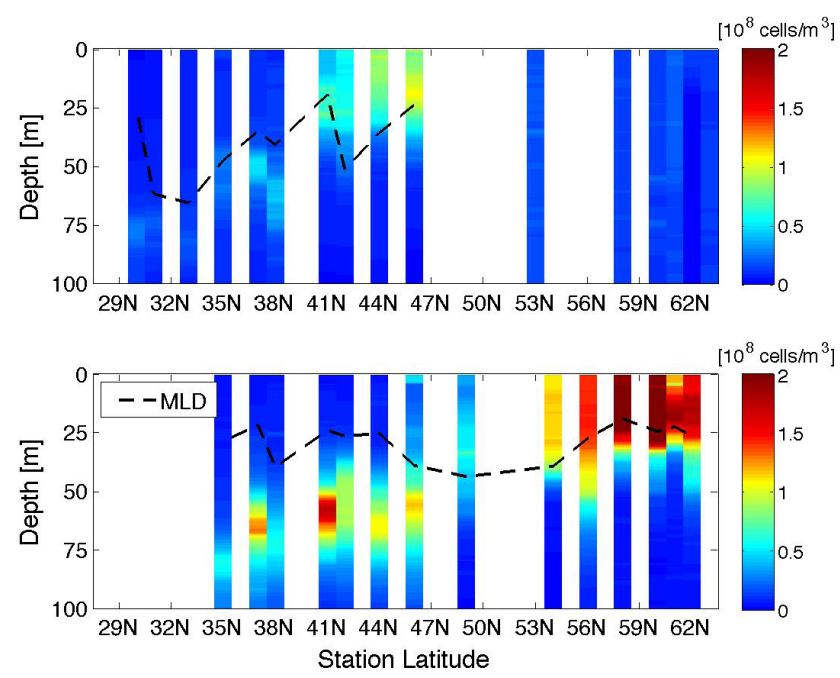

Figure 3. Phytoplankton cell concentration converted from the interpolated and smoothed Chl $a$ concentrations measured during the spring (top) and summer (bottom) cruise. The dashed curve indicates the MLD.

content ratio and the nutrient content: $\mathrm{Chl} a$ ratio given by Ryabov et al. (2010) and Omta et al. (2009), respectively.

During spring, well-mixed stations at the northern part of the transect show a homogeneous distribution of phytoplankton over the first $100 \mathrm{~m}$. Further south and especially during summer, stratification forces the phytoplankton to grow either within the mixed layer in a UCM, or to grow below the mixed layer in a DCM.

Figure 3 as well as the MODIS Aqua data in Fig. 1b show that the further north one observes the surface $\mathrm{Chl} a$ concentration, the later the transition from the UCM to the DCM happens, if at all. At latitudes north of $45^{\circ} \mathrm{N}$ surface concentrations remain relatively high throughout the entire light season, while regions south of $45^{\circ} \mathrm{N}$ exhibit very low Chl $a$ concentrations during summer. Irrespective of the latitude, locally and temporally restricted surface $\mathrm{Chl} a$ maxima are also seen independent of the stratification cycle. These maxima have been suggested to be connected to ocean eddies (Mahadevan et al., 2012).

In situ measurements of PAR at the water surface and over the water column were measured with optical sensors attached to a CTD profiler. The profiles are used to determine the optical parameters (see Appendix A).

In situ measurements of phosphate $\left(\mathrm{PO}_{4}\right)$, nitrogen dioxide $\left(\mathrm{NO}_{2}\right)$ and nitrate $\left(\mathrm{NO}_{3}\right)$ show that there is a gradient in the nutricline between south and north (van de Poll et al., 2013). According to the measured data, the water column provides sufficient nutrients for the phytoplankton to grow close to the surface in the northern stations, a so-called mesotrophic state. At stations further south the surface layer is practically depleted of nutrients and therefore oligotrophic. The transition between the oligotrophic and the mesotrophic stations lies 
at about $40^{\circ} \mathrm{N}$ during the spring cruise and at about $45^{\circ} \mathrm{N}$ during the summer cruise. The comparison with the $\mathrm{Chl} a$ profiles in Fig. 3 shows that these are also the latitudes of transition from an deep chlorophyll maximum (DCM) to an upper chlorophyll maximum (UCM).

In the model only one generalised nutrient concentration is used and the measurements of $\mathrm{PO}_{4}, \mathrm{NO}_{2}$ and $\mathrm{NO}_{3}$ are in the following summed up and generalised as nutrient concentration.

\section{The phytoplankton model}

The phytoplankton model is a simple one-dimensional model based on the advection-reaction-diffusion models of Huisman and Sommeijer (2002) and Ryabov et al. (2010). Figure 4 provides a sketch of the basic model setup and the processes controlling growth and phytoplankton distribution in the model. Phytoplankton cells need nutrients and light to grow and their number is reduced at a constant rate representing sedimentation and grazing. Sunlight penetrates the water at the surface and its intensity decreases exponentially with depth due to the background attenuation of sea water and the absorption by phytoplankton cells. Vertical mixing is represented as a depth-dependent diffusion coefficient and it distributes nutrients and phytoplankton cells over the onedimensional water column.

\subsection{Governing equations}

In a water column of depth $Z_{\mathrm{b}}$ the concentration of phytoplankton cells at time $t>0$ and vertical position $z \in\left[0, Z_{\mathrm{b}}\right]$, where $z=0$ indicates the surface and $z$ is positive downwards, is denoted by $P(z, t)$ (Fig. 4). The two controlling factors for phytoplankton growth are the concentration of nutrients $N(z, t)$ and the intensity of light $I(z, t)$. The coupling of nutrient and phytoplankton dynamics is described by the following two equations (Ryabov et al., 2010):

$$
\begin{aligned}
\frac{\partial P}{\partial t} & =\text { growth }- \text { loss }- \text { sinking }+ \text { vertical mixing } \\
& =\mu(N, I) P-m P-v \frac{\partial P}{\partial z}+\frac{\partial}{\partial z}\left[K_{T}(z) \frac{\partial P}{\partial z}\right],
\end{aligned}
$$

$$
\begin{aligned}
\frac{\partial N}{\partial t} & =- \text { uptake }+ \text { recycling }+ \text { vertical mixing } \\
& =-\alpha \mu(N, I) P+\varepsilon \alpha m P+\frac{\partial}{\partial z}\left[K_{T}(z) \frac{\partial N}{\partial z}\right],
\end{aligned}
$$

where $\mu(N, I)$ describes the local growth. Furthermore, $m$ is the mortality, $v$ is the sinking velocity, $K_{T}(z)$ is the depthdependent vertical mixing coefficient, $\alpha$ is the nutrient content of a phytoplankton cell and $\varepsilon$ is the nutrient recycling coefficient.

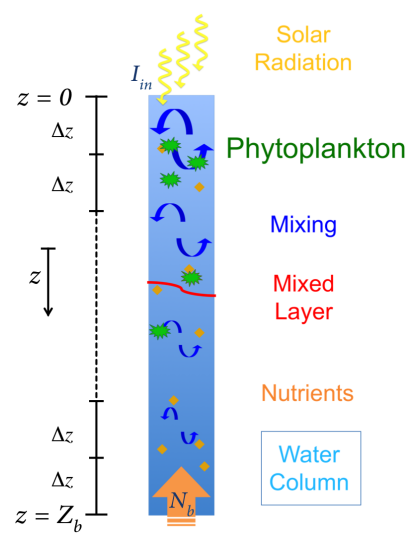

Figure 4. Schematic representation of the processes and the setup of the model.

No-flux conditions are assumed at the surface $z=0$ for both the phytoplankton concentration and the nutrient concentration. At the bottom boundary, $z=Z_{\mathrm{b}}$, the nutrient concentration is prescribed as constant value $N_{\mathrm{b}}$, which represents an infinite source of nutrients in the deep ocean. The magnitude of this source is latitude dependent and based on measurements as discussed below and shown in Table 3. The initial phytoplankton concentration $P$ is based on the measured profiles. At the bottom boundary the no-flux condition is applied. Since the boundary lies well below the euphotic layer, this is only important for cases of very strong mixing. Generally, the cells die before they reach the bottom boundary, which is in agreement with the measurements. Further description as well as standard values of the parameters can be found in Table 1 .

Growth and loss couple $P$ to $N$ via the uptake of nutrients and the partial recycling of dead phytoplankton cells. The growth rate $\mu(N, I)$ has a strong local dependence on the available resources and is written as

$\mu(N, I)=\mu_{\max } \min \left(\frac{N}{H_{N}+N}, \frac{I}{H_{I}+I}\right)$,

where $\mu_{\max }$ is the maximum growth rate of phytoplankton and $H_{N}$ and $H_{I}$ are the half-saturation constants of nutrientlimited growth and of light-limited growth, respectively. For example, the value of $H_{N}$ is relatively low for species which are well adapted to nutrient-limited regimes.

The intensity of light as a function of vertical position $z$ and time $t$ is given by the Beer-Lambert equation

$I(z, t)=I_{\text {in }} \exp \left[-K_{\mathrm{bg}} z-k \int_{0}^{z} P(\xi, t) \mathrm{d} \xi\right]$,

where $I_{\text {in }}$ denotes the intensity of the incoming light at the surface of the water column. The intensity of light within the water column decreases with depth due to a constant background attenuation represented by $K_{\mathrm{bg}}$. Additionally, each 
Table 1. Standard values used in the model.

\begin{tabular}{|c|c|c|c|}
\hline Symbol & Description & Units & Value \\
\hline & System parameters & & \\
\hline$Z_{\mathrm{b}}$ & Depth of the system & $\mathrm{m}$ & 150 \\
\hline$I_{\text {in }}$ & Incident light intensity & $\mu \mathrm{mol}$ photons $\mathrm{m}^{-2} \mathrm{~s}^{-1}$ & $390-625$ \\
\hline$N_{\mathrm{b}}$ & Nutrient concentration at $Z_{\mathrm{b}}$ & mmol nutrients $\mathrm{m}^{-3}$ & $5.7-12.7$ \\
\hline \multirow[t]{2}{*}{$K_{T}$} & Vertical mixing coefficient (depth dependent) & $\mathrm{m}^{2} \mathrm{~s}^{-1}$ & $1.0 \times 10^{-5}-0.85$ \\
\hline & Optical parameters & & \\
\hline$K_{\text {bg }}$ & Background attenuation of sea water & $\mathrm{m}^{-1}$ & 0.032 \\
\hline \multirow[t]{2}{*}{$k$} & Absorption coefficient of phytoplankton & $\mathrm{m}^{2}$ cell $^{-1}$ & $1.0 \times 10^{-9}$ \\
\hline & Biological parameters & & \\
\hline$\mu_{\max }$ & Maximum specific growth rate & $\mathrm{h}^{-1}$ & 0.04 \\
\hline$H_{I}$ & Half saturation constant of light limited growth & $\mu \mathrm{mol}$ photons $\mathrm{m}^{-2} \mathrm{~s}^{-1}$ & $85-186$ \\
\hline$H_{N}$ & Half saturation constant of nutrient limited growth & mmol nutrients $\mathrm{m}^{-3}$ & $0.0425-0.1001$ \\
\hline$m$ & Specific loss rate & $\mathrm{h}^{-1}$ & 0.01 \\
\hline$\alpha$ & Nutrient content of phytoplankton & mmol nutrients cell ${ }^{-1}$ & $1.0 \times 10^{-9}$ \\
\hline$\varepsilon$ & Nutrient recycling coefficient & - & $0.034-0.5$ \\
\hline \multirow[t]{2}{*}{$v$} & Sinking velocity & $\mathrm{mh}^{-1}$ & 0.042 \\
\hline & Numerical parameters & & \\
\hline$\Delta z$ & Spatial step & $\mathrm{m}$ & 0.25 \\
\hline$\Delta t$ & Temporal step & $\mathrm{h}$ & 240 \\
\hline
\end{tabular}

phytoplankton cell absorbs light which leads to a shading effect on the whole water column below the cell. This effect is represented by the integral over $P$ times $k$ in Eq. (5).

The total nutrient budget consists of all nutrients stored as nutrients and as phytoplankton cells. In a steady state it is constant and from Eqs. (2) and (3) (including the boundary conditions) it follows that

$$
\left.K_{T}\left(Z_{\mathrm{b}}\right) \frac{\partial N}{\partial z}\right|_{Z_{\mathrm{b}}}=(1-\varepsilon) m \alpha \int_{0}^{Z_{\mathrm{b}}} P(z) \mathrm{d} z
$$

This means that in the steady state the nutrient flux coming into the system at the bottom boundary is balanced by the nutrient loss due to the inefficient recycling.

\subsection{Numerical implementation}

All model parameters are given in Table 1. Parameters for which a range of values is given change with latitude and season of the observation. All parameters remain constant during one model run. The depth of the system is chosen to be well below the euphotic layer and the other system parameters can be directly defined from measurements. Initial profiles of the phytoplankton concentration and the nutrient concentration are read in from the observations. To fulfil the boundary conditions, the nutrient concentration at $Z_{\mathrm{b}}$ is fixed to the $10 \mathrm{~m}$ mean of the deepest values per station. The vertical mixing is defined by the measured, vertically varying mixing profiles of $K_{T}(z)$ shown in Fig. 2.

The optical parameters and some of the biological parameters will be determined from the observations in the following section. All other biological parameters are based on Ryabov et al. (2010).

To solve the differential Eqs. (2) and (3) the NAG D02EJF routine is used (see for more details http://www.nag.co.uk). The temporal step size for the integration is determined by the routine itself to guarantee that the integration is stable and efficient at the same time. The model state is saved to a file every 10 days. The inhomogeneous profiles of vertical mixing can vary by three orders of magnitude. To guarantee a sufficient spatial resolution a grid spacing of $\Delta z=0.25 \mathrm{~m}$ is applied. In all simulations, the model is run a minimum of 1000 days and until it reaches an equilibrium. To determine the equilibrium the relative change per time step is defined as

$$
\begin{aligned}
& R= \\
& \max \left(\left|\frac{P(t)-P(t+\Delta t)}{P(t)}\right|,\left|\frac{N(t)-N(t+\Delta t)}{N(t)}\right|\right),
\end{aligned}
$$

where $|\cdot|$ defines the absolute value. The equilibrium is reached for $R \leq 1 \times 10^{-4}$.

Before applying realistic vertical mixing profiles, results in Huisman et al. (2006) and Ryabov et al. (2010) are successfully reproduced to test the model. These computations have been done with homogeneous vertical mixing in the 
non-stratified case and an artificial vertical mixing profile in the stratified case (based on a generalised Fermi function, see Ryabov et al., 2010, for more details).

\section{Calibration of the model}

The biological data of the STRATIPHYT project show that the Chl $a$ profiles originate from compositions of different phytoplankton species (van de Poll et al., 2013). Simulating the phytoplankton growth at STRATIPHYT with the simple model presented here (one generalised phytoplankton community) requires the calibration of the biological parameters to the measured data.

The optical parameters are determined by combining Eq. (5) with the measured light profiles. Details of the method are described in the Appendix and the results are given in Sect. 4.1.

In Sect. 4.2, two of the biological parameters are calibrated in order to reproduce the observations at three different stations. The three sets of parameters obtained are assumed to characterise the phytoplankton community at a given location and during the given season. The results of the optical and biological parameter calibration are discussed in Sect. 4.3.

\subsection{Optical parameters $K_{\mathrm{bg}}$ and $k$}

The transmittance of light in water can be affected by waves and a high concentration of small air bubbles at the surface as well as phytoplankton, sediments and dissolved organic material in the water column. Since surface effects are very localised and sediment concentrations are very low in open water they are both not taken into account in the analysis. Our aim is rather to identify the characteristics of the light attenuation due to the two major contributions: the background attenuation of sea water $K_{\mathrm{bg}}$ and the absorption coefficient of phytoplankton $k$.

Figure A1 in the Appendix shows an example of CTD data of fluorescence, surface irradiance and corrected irradiance (percentage of surface irradiance measured at depth, see Appendix A for definitions and calculations). For the calibration the fluorescence and corrected irradiance profiles are divided into two sections: a Chl $a$ free section at the bottom of the euphotic layer to determine $K_{\mathrm{bg}}$ and a section with a high Chl $a$ concentration in the euphotic layer to determine $k$.

Figure A2 shows that values of $K_{\text {bg }}$ derived from DCM states are homogeneously spread around their mean of $0.032 \mathrm{~m}^{-1}$ and more scattered in spring. Stations with a UCM tend to show higher values. Homogeneously mixed stations were not qualified for the analysis since they do not have Chl $a$ free sections. Since the UCM states can be effected by e.g. backscattering (see Sect. 4.3 for detailed discussion), the value of $K_{\mathrm{bg}}$ is set to $0.032 \mathrm{~m}^{-1}$.
Based on the determined $K_{\mathrm{bg}}$ value, results for $k$ are shown in Fig. A3. For the summer data, values have a mean of $5.9 \pm 1.9 \times 10^{-10} \mathrm{~m}^{2}$ cell $^{-1}$ and the state of the station does not seem to influence this result. The mean $k$ derived from the spring data is more than twice as high. To take both seasons into account, $k=10^{-9} \mathrm{~m}^{2}$ cell ${ }^{-1}$ is chosen.

\subsection{Biological parameters $H_{I}, H_{N}$ and $\varepsilon$}

When calibrating the biological model parameters with the help of the observations, the model is run with a certain parameter set until it reaches an equilibrium and the result is compared to the observations. In order to efficiently compare the model result with the observations the least squares method (LSM) as implemented in the NAG E04FCF (an unconstrained optimisation solver) is used. The routine changes the biological parameters with the aim of minimising the sum of squares $S$ defined as

$S=\sqrt{\sum_{i}\left(1-\frac{C_{\mathrm{mod}}^{i}}{C_{\mathrm{meas}}^{i}}\right)^{2}}$,

where $C_{\text {mod }}^{i}$ and $C_{\text {meas }}^{i}$ are characteristics of the model results and the observations, respectively. The definition of these characteristics depends on the state of the observations. In the case of a DCM, the main characteristics are the depth and the value of the DCM. In the case of a UCM, the main characteristics are the mean phytoplankton concentration and the mean nutrient concentration within the ML. This categorisation into states and characteristics needs to be done because the model cannot reproduce the small-scale vertical variations in the observations. The normalisation by $C_{\text {meas }}^{i}$ allows to compare values of different orders equally (e.g. the depth with the concentration of $\mathcal{O}(P)=8$ ).

The phytoplankton growth is controlled by several environmental factors, such as light and nutrient availability. The limitation of one factor can lead to dramatic changes in concentration and vertical location. A DCM is known to establish due to nutrient limitation in the upper layer, while a UCM establishes when sufficient nutrients are available at the surface and it limits the growth at depth due to a low light availability below the ML. For the model it follows that the controlling growth parameter in the case of the DCM should be the half-saturation constant of nutrient-limited growth $H_{N}$ and in case of the UCM, it should be the half-saturation constant of light-limited growth $H_{I}$.

Additionally the recycling coefficient $\varepsilon$, which connects the nutrient budget to the phytoplankton budget (see Eq. 6), is calibrated. This coefficient incorporates two important mechanisms, the sedimentation and the remineralisation of dead phytoplankton cells. Choosing a constant value is a crude simplification of the model, which is improved by the calibration to the biochemical environment. In contrast to $m$ and $\alpha$, which also play a central role in Eq. (6), $\varepsilon$ does not directly 
impact the phytoplankton concentration but only indirectly due to the change in the local nutrient concentration.

The measured profiles are assumed to be in a steady state. Since the model is incapable of reproducing the fine-scale variations of the vertical profiles, the calibration focuses on two main features of the measured profile. These features depend on the state of the system (DCM, UCM or homogeneously mixed) and have to be reproduced by the model which makes it possible to calibrate the parameters $\varepsilon$ and $H_{I}$, respectively $H_{N}$. In the case of a DCM dominant features are the depth of the DCM and its associated maximum phytoplankton concentration. In the case of a UCM state, the mean phytoplankton concentration and the mean nutrient concentration within the ML are defining the dominant features.

The model parameters are calibrated to two stations of the summer cruise that have different steady states, a DCM and a UCM. The DCM is measured at the southern part of the track $\left(40.5^{\circ} \mathrm{N}\right)$ and the UCM at the northern part $\left(60.7^{\circ} \mathrm{N}\right)$. These stations are in the following referred to as the southern and northern station, respectively. Additionally, a station of the spring cruise at $44.3^{\circ} \mathrm{N}$ is used. The observations show a clear UCM in spring and a deep DCM in summer (see Fig. 3). This station is referred to as the transition station, because of the change of states with the seasons.

In Table 3 the value ranges for the calibration and the final results as well as the station-specific boundary conditions are given. The fixed biological parameters are based on values of previous work by Ryabov et al. (2010) and a number of runs to test the sensitivity and behaviour of the model (Table 1).

\subsubsection{The southern station}

At the southern station, the measured vertical mixing profile is generally about four times stronger in the upper $25 \mathrm{~m}$ than in the lower $75 \mathrm{~m}$ (Fig. 5, right panel). Two peaks between 60 and $70 \mathrm{~m}$ as well as around $90 \mathrm{~m}$ depth stand out from the relatively low mixing at depth. In the left panel, the measured phytoplankton concentration has a maximum of $1.72 \times 10^{8}$ cells $^{-3}$ at $58.25 \mathrm{~m}$ depth, clearly showing a DCM. The respective model result has a negligible smaller maximum concentration $(-0.0019 \%)$ at $52.25 \mathrm{~m}$ depth. The spread of the measured phytoplankton concentration is remarkably wider than the modelled concentration. The nutrient concentration shows for both data sets a similar distribution from the surface down to the DCM, where concentrations are first very low and then start to increase at the DCM. Below the DCM, the in situ data increase faster than the model data. The model data show a linear slope below $100 \mathrm{~m}$ depth due to the fixed nutrient concentration at the bottom and the uniform mixing.

The light intensity decays exponentially and has very low values at depths of the DCM and further below. Both profiles have a similar shape, but the modelled profile has in general higher values and is shifted slightly upwards as is the modelled DCM. The effect of the DCM on the light intensity due

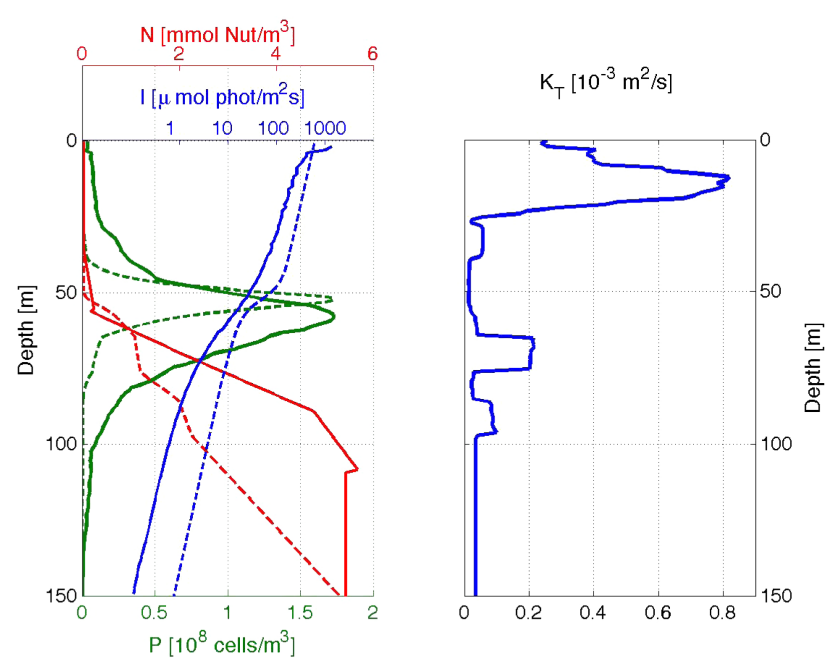

Figure 5. Measurements (solid lines) and model results (dashed lines) at the southern station. Left panel: phytoplankton concentration (green), nutrient concentration (red) and light intensity (blue). The LSM is based on the depth and the value of the DCM. Right panel: vertical mixing coefficient $K_{T}$.

to the shading is clearly seen in the step of the modelled light intensity profile, while the effect on the measured profile is less strong.

\subsubsection{The northern station}

At the northern station, the vertical is very inhomogeneous with moderate mixing in the upper $25 \mathrm{~m}$, very weak mixing around $25 \mathrm{~m}$ depth, the strongest peak around $40 \mathrm{~m}$ depth and weaker mixing below $50 \mathrm{~m}$ depth (Fig. 6, right panel). In the left panel, the measured phytoplankton concentration shows a significant UCM with a mean of $1.55 \times 10^{8}$ cells m$^{-3}$ in the ML. The cell concentration increases from the surface to the bottom of the ML and decreases exponentially below. The modelled result shows a high surface concentration with a mean of $1.56 \times 10^{8}$ cells $^{-3}$ that decreases slightly towards the bottom of the ML and then drops rapidly below. The nutrient concentration is low in the ML with a mean of $2.24 \mathrm{mmol}$ nutrients $\mathrm{m}^{-3}$ and increases rapidly below. In contrast to the southern station, the ML is not depleted of nutrients. Since the model parameters are calibrated to the mean nutrient concentration in the ML, the model result (mean of $2.26 \mathrm{mmol}$ nutrients $\mathrm{m}^{-3}$ ) fits well to the measured results in the ML. Below the ML the concentration increases first in several small steps and then linearly. The steps are located at depths where the vertical mixing is very low. The light intensity profile decreases quickly over depth due to the high phytoplankton cell concentration within the ML, which is especially apparent in the modelled profile. 

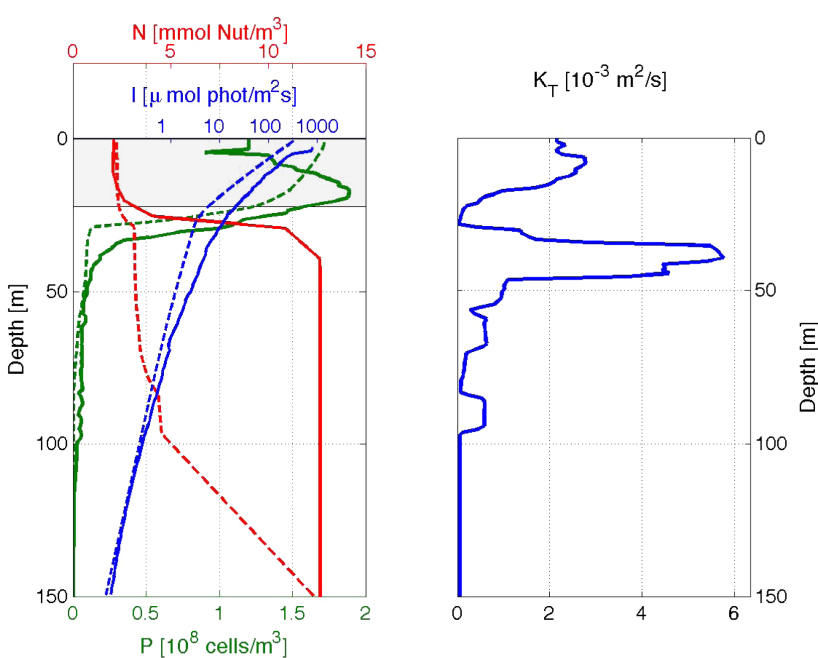

Figure 6. Measurements (solid lines) and model results (dashed lines) at the northern station. Left panel: phytoplankton concentration (green), nutrient concentration (red) and light intensity (blue). The LSM is based on the mean phytoplankton concentration and the mean nutrient concentration in the ML (grey area). Right panel: vertical mixing coefficient $K_{T}$.

\subsubsection{The transition station}

At the transition station, strong mixing in a well-defined ML with $35.6 \mathrm{~m}$ depth and low mixing below the ML is measured (Fig. 7, right panel). In the left panel, the phytoplankton concentration shows an UCM with lower concentrations (mean of $7.21 \times 10^{7}$ cells m$^{-3}$ ) than at the northern station, which is also differently distributed: the highest concentration is close to the surface and it decreases exponentially between 30 and $50 \mathrm{~m}$ depth. The modelled phytoplankton concentration behaves similar as at the northern station, where the concentration is maximal at the surface, decreases slightly towards the bottom of the ML and then decreases exponentially below. The mean phytoplankton concentration in the ML is $7.19 \times 10^{7}$ cells $\mathrm{m}^{-3}$. The measured nutrient concentration is very homogeneously distributed over the ML with a mean value of $1.54 \mathrm{mmol}$ nutrients $\mathrm{m}^{-3}$. The concentration increases just below the ML where it soon reaches its bottom boundary value. The mean value of the modelled nutrient concentration is also $1.54 \mathrm{mmol}$ nutrients $\mathrm{m}^{-3}$. The almost homogeneous vertical mixing below the ML leads to a smooth increase of modelled nutrients towards the bottom. The measured irradiance intensity has a comparatively low surface irradiance and decreases strongly with depth. The modelled irradiance profile is based on a higher irradiance and is not capable to capture the strong gradient.

\subsection{Discussion on the model calibration}

As comparing the results of highly idealised models, such as the one used here, to in situ measurements and using them for

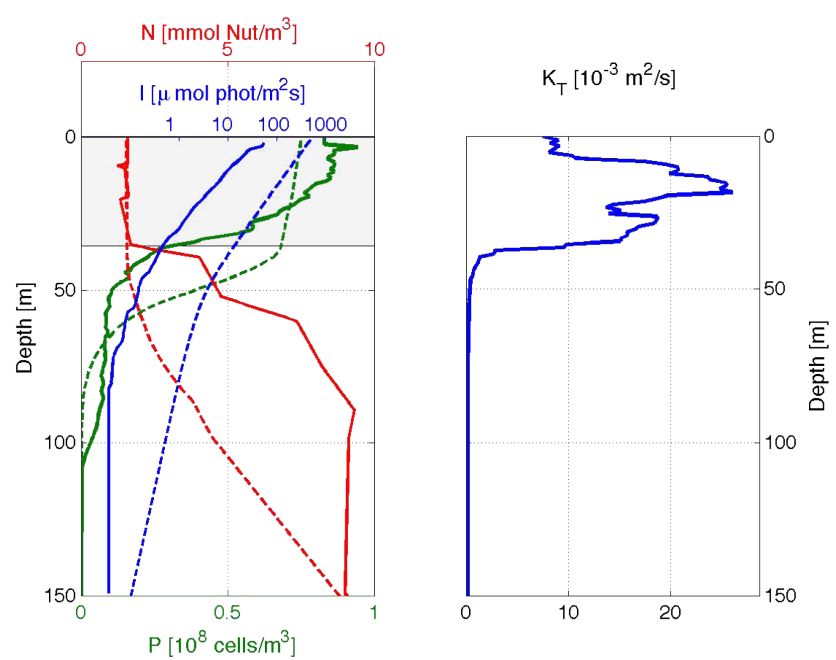

Figure 7. Measurements (solid lines) and model results (dashed lines) at the transition station. See caption of Fig. 6 for details.

the calibration of model parameters may raise concerns (see e.g. Evans et al., 2013), we provide in this section a rather extensive discussion of the model calibration results.

\subsection{1 $\quad K_{\mathrm{bg}}$ and $k$}

In general all values for $K_{\mathrm{bg}}$ as well as for $k$, shown in Figs. A2 and A3, lie in the range of values used in other models (see Table 2). The relatively high standard deviation at some stations can be partially explained by the varying fraction of light which is reflected at the surface due to the zenith angle. When the sun stands low, a higher fraction of the incoming light will be reflected already at the water surface (Mobley, 1994; Kirk, 2011). This effect leads to a lower ratio of the intensity of light in the water column to the intensity of the incoming light and is primarily independent of the optical properties of the water column. To avoid extreme influence of the solar angle, data measured early in the morning and late in the afternoon are not taken into account.

The values of $K_{\mathrm{bg}}$ during the summer cruise (Fig. A2b) are characterised by two different domains. Data of stations with a well-defined DCM lead to values of $K_{\mathrm{bg}}$ that are close to their mean of $0.032 \mathrm{~m}^{-1}$. For stations with phytoplankton distributions dominated by a UCM, $K_{\text {bg }}$ increases with increasing latitude. A possible explanation of this difference is the effect of particulate backscatter which increases the absorption and becomes more important at higher latitudes (Siegel et al., 2005).

The analysis of the optical properties during the spring cruise is mainly limited to the DCM stations. For homogeneously mixed stations our method cannot be used since it is not possible to distinguish between the effect of phytoplankton absorption and $K_{\text {bg }}$ in such systems. The results in Fig. A2 show that $K_{\text {bg }}$ values are more widely spread for the spring cruise and the standard deviation can be up to $100 \%$. 
Table 2. Value ranges used in other models.

\begin{tabular}{|c|c|c|c|c|c|}
\hline Ref. & $\begin{array}{r}K_{\mathrm{bg}} \\
{\left[\mathrm{m}^{-1}\right]}\end{array}$ & {$\left[10^{-10} \mathrm{~m}^{2}\right.$ cell $\left.^{-1}\right]$} & {$\left[\mu\right.$ mol photons m $\left.{ }^{-2} \mathrm{~s}^{-1}\right]$} & {$\left[\begin{array}{r}H_{N} \\
{\left[{\text { mmol nutrients } \mathrm{m}^{-3}}^{-3}\right.}\end{array}\right.$} & $\begin{array}{r}\varepsilon \\
{[-]}\end{array}$ \\
\hline Losa et al. (2004) & 0.04 & $0.3^{\mathrm{a}}$ & - & 0.3 & 0.05 \\
\hline Fiechter (2012) & 0.067 & $0.4^{\mathrm{a}}$ & - & 1.0 & - \\
\hline Huisman and Sommeijer (2002) & 0.2 & 0.15 & 30 & - & - \\
\hline Valenti et al. (2012) & 0.045 & 6.0 & 20 & 0.0425 & 0.5 \\
\hline Mellard et al. (2011) & 0.1 & 0.1 & 50 & $0.032^{\mathrm{b}}$ & 0.9 \\
\hline Thi et al. (2005) & 0.2 & $0.15-0.3$ & $10-20$ & - & 0.01 \\
\hline \multirow[t]{2}{*}{ Liccardo et al. (2013) } & 0.05 & 6.0 & 20 & 0.02 & - \\
\hline & $0.04-0.2$ & $0.15-6.0$ & $10-50$ & $0.02-1.0$ & $0.05-0.9$ \\
\hline
\end{tabular}

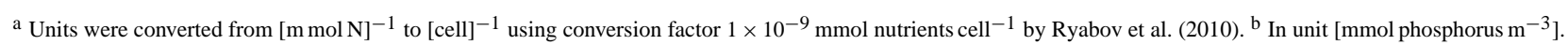

Still most of the values are close to the mean of the summer data, $0.032 \mathrm{~m}^{-1}$. This value is also consistent with those determined from the detailed (spectrally resolved) measurements in the clearest oceanographic waters (Morel et al., 2007) and hence it is used for the model parameterisation.

Figure A3 shows that $k$ derived from the spring data shows higher values as well as a wider spread compared to the results derived from the summer data. The origin of these high variations can be manifold (e.g. the biological composition and species-dependent properties) and an explanation is outside the scope of this paper. The strong consistency of the summer results and the comparison with the literature (see Table 2) would suggest choosing $k=6.0 \times 10^{-10} \mathrm{~m}^{2}$ cell $^{-1}$. Instead the mean of the spring and summer result, $k=$ $10^{-9} \mathrm{~m}^{2}$ cell $^{-1}$ is chosen to represent the whole phytoplankton community.

\subsection{2 $H_{I}, H_{N}$ and $\varepsilon$}

Before applying the LSM method a series of sensitivity tests were performed to study the behaviour and the robustness of the model. The tests were based on two standard model setups with biological parameters values calibrated to lead to a DCM and a UCM state, respectively. Biological parameters, like the growth rate and the recycling rate, as well as $N_{\mathrm{b}}$ and $I_{\text {in }}$ have been varied (one at the time) over a range of realistic values as measured or used in the literature. The most important outcome of this study is that none of these parameter variations shows unexpected growth dynamics. The phytoplankton concentration for the DCM parameterisation responds generally quicker to changes in the biological or environmental parameters than the phytoplankton concentration for the UCM parameterisation. Generally the growth function is controlled by one limited resource, light or nutrients, which also determines the equilibrium state. Changes of the half-saturation constant based on the other resource have less effect on the growth. The tests also show a high sensitivity to parameters which connect to the total nutrient budget, like the nutrient concentration at the bottom of the system
$N_{\mathrm{b}}$ and the recycling coefficient $\varepsilon$. While the first is determined by measurements, the latter involves more complex processes like grazing, remineralisation and sedimentation.

Generally, the results of the LSM for $H_{N}$ and $\varepsilon$ are in the range of commonly used values (see Tables 3 and 2) and their observed properties are similar to previous studies of ecological model parameters (e.g. Beckmann and Hense, 2007). Both $H_{I}$ values are an order higher than the common values. Possible reasons and explanations are discussed per station in the following.

At the southern station the best result of the LSM was found for $H_{N}=0.10014 \mathrm{mmol}$ nutrients $\mathrm{m}^{-3}$ and $\varepsilon=$ 0.61703 . The profiles in Fig. 5 show that the main characteristics of all three environmental variables are well reproduced. The recycling rate at the southern station is higher than the standard value, underlining that the supply of nutrients is an essential driver for the DCM state. Sensitivity studies have shown (results not presented here) that the equilibrium state is sensitive to changes of the half-saturation constant $H_{I}$. Considering that a DCM is by default a very sensitive state that establishes as a compromise between light and nutrient limitation, it is not surprising that the growth is affected by changes of the biological parameters. Nevertheless, since nutrient limitation is the driving force behind the DCM, the calibration of $H_{N}$ and $\varepsilon$ with a fixed $H_{I}$ appears to be a reasonable choice and results show a good representation of the measured profiles.

At the northern station the best result of the LSM was found for $H_{I}=148.81 \mu \mathrm{mol}$ photons $\mathrm{m}^{-2} \mathrm{~s}^{-1}$ and $\varepsilon=$ 0.4018 . The high value of $H_{I}$ indicates that the light availability at the surface is very high, even though the incoming light intensity is almost half the strength of the incoming irradiance at the southern station. The strong attenuation due to the phytoplankton concentration leads to a rapid decay over depth. The light intensity goes below $10 \mu$ mol photons $\mathrm{m}^{-2} \mathrm{~s}^{-1}$ at not even $20 \mathrm{~m}$ depth, while at the southern station this value is crossed at $72 \mathrm{~m}$ depth. It is therefore not only the strength of the light availability, but 
also the effective time a cell spends in the light. Due to the strong mixing in the ML the cells are moved more actively towards the surface and down again. To achieve an effective limitation of growth due to the light intensity, the halfsaturation constant $H_{I}$ needs to be high in order to control the growth. Remineralisation is less effective at the northern station than at the southern station. In terms of the nutrient budget, this means that nutrients are more effectively resupplied from the bottom boundary at the northern station even though vertical mixing close to the boundary is weaker at the northern station. This is possible due to the large $N_{\mathrm{b}}$ which is more than double the bottom concentration of the southern station.

At the transition station the parameter set $H_{I}=$ $186.7 \mu$ mol photons $\mathrm{m}^{-2} \mathrm{~s}^{-1}$ and $\varepsilon=0.034$ was found. The value of $H_{I}$ is even higher here than at the northern station. The possible explanations are similar to the ones given for the northern station and the intensification of the effect can be explained by the higher incoming radiation at the transition station. The recycling rate is very low, but compares to the one given by Losa et al. (2004). The main source of nutrients is therefore the resupply from the bottom boundary and over $95 \%$ of the nutrients taken up by phytoplankton are lost.

Remineralisation rates depend on a number of factors like grazing, nutrient composition and temperature (e.g. Brea et al., 2004), which can all lead to the differences shown for the three reference stations.

In Fig. 8a the relative change per time step as given in Eq. (7) is shown. To reach the equilibrium the model takes 7820 days for the southern station, 5980 days for the transition station, and 12150 days for the northern station. The time is normalised such that the three graphs can be shown in one figure. All stations undergo rapid changes during the first quarter of the run and then approach their final state with an exponentially decreasing rate of change. The small wiggles are numerical artefacts. The temporal evolution of the sum of squares $S$ as given in Eq. (8) is shown in Fig. 8b. The southern station deviates only a little from its initial state and remains close to its final value after $50 \%$ of the time to reach the equilibrium. Results of the northern and the transition station undergo a greater change in the beginning of the run and approach their equilibrium state exponentially. Their result is closer to the measurements and undergoes changes until the whole system is in equilibrium. This stands in contrast to the result of the southern station where the value of $S$ remains constant even though the model does not reached its equilibrium for a further 3000 days.

\section{Sensitivity to turbulent vertical mixing}

Based on the model calibrations of Sect. 5.1 the vertical mixing profiles of the STRATIPHYT cruise are applied to the three reference states to study the sensitivity of the phytoplankton growth to changes in the vertical mixing. In
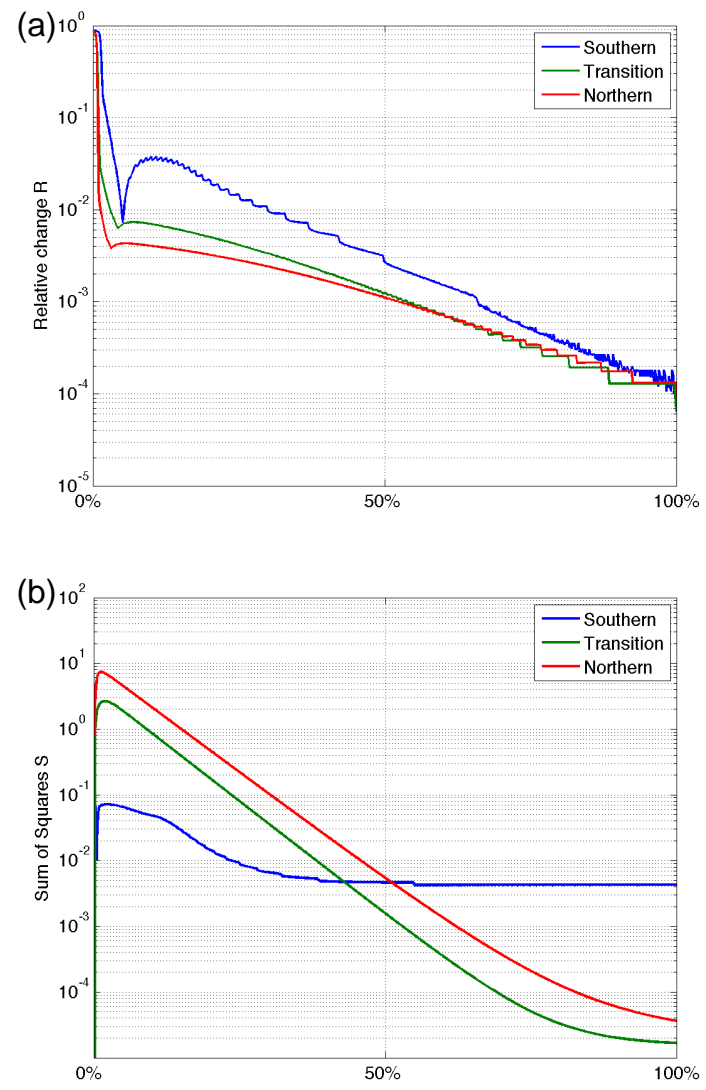

Figure 8. Temporal evolution of (a) the relative change of the system per time step $R$ and (b) the sum of squares $S$ for the three reference stations. On the $x$ axis the time is given as the percentage of the total duration until the equilibrium is reached. The $y$ axis is in logarithmic scaling.

Sect. 2.2 the observed vertical mixing coefficients along the zonal transect from 29 to $63^{\circ} \mathrm{N}$ for the STRATIPHYT cruises in summer 2009 and spring 2011 were presented. In this section these vertical mixing profiles (for both spring and summer cruises) are applied to the three calibrations of the model, while the other model parameters remain fixed. The idea is to simulate different mixing scenarios at one location. For this purpose the mixing profiles are treated as realistic mixing states of the northern Atlantic which can occur at these stations. To facilitate the discussion of the result the profiles are rearranged according to their mean strength in mixing (Fig. 9). The strong variability within one mixing profiles makes the categorisation of the profiles difficult. Instead of the mean mixing strength other characteristics, e.g. MLD, could have been chosen. Eventually, the actual sensitivity analysis will be independent of the order of the profiles.

\subsection{Phytoplankton profiles}

The distribution of states in Fig. 10 shows that the three calibrations respond differently to the vertical mixing. As could 
Table 3. Description of the reference stations with the boundary conditions for the bottom nutrient concentration $N_{\mathrm{b}}$ and the incoming light intensity $I_{\text {in }}$ as well as the biological parameters calibrated with the LSM. Numbers in parentheses give the range of values tested during the calibration.

\begin{tabular}{|c|c|c|c|c|c|c|c|}
\hline $\begin{array}{l}\text { Description } \\
\& \text { Latitude }\end{array}$ & $\begin{array}{l}\text { Cruise } \\
\& \text { Date }\end{array}$ & {$\left[\begin{array}{c}N_{\mathrm{b}} \\
{\left[{\text { mmol nutrients } \mathrm{m}^{-3}}^{-3}\right]}\end{array}\right.$} & $\stackrel{I_{\text {in }}}{\left[\mu \text { mol photons } \mathrm{m}^{-2} \mathrm{~s}^{-1}\right]}$ & $\begin{array}{c}H_{N} \\
{\left[\text { mmol nutrients } \mathrm{m}^{-3}\right]}\end{array}$ & $\begin{array}{c}H_{I} \\
{\left[\mu \text { mol photons } \mathrm{m}^{-2} \mathrm{~s}^{-1}\right]}\end{array}$ & $\begin{array}{l}\varepsilon \\
-\end{array}$ & $\begin{array}{l}S \\
-\end{array}$ \\
\hline $\begin{array}{l}\text { Southern } \\
40.5^{\circ} \mathrm{N}, 13.2^{\circ} \mathrm{W}\end{array}$ & $\begin{array}{c}\text { Summer } \\
\text { 23 July } 2009\end{array}$ & 5.3 & 625 & $\begin{array}{c}0.10014 \\
\left(1 \times 10^{-3}-1.5\right)\end{array}$ & $\begin{array}{c}85 \\
\text { (fix) }\end{array}$ & $\begin{array}{c}0.61703 \\
(0.302-0.802)\end{array}$ & 0.0043 \\
\hline $\begin{array}{l}\text { Northern } \\
60.7^{\circ} \mathrm{N}, 19.3^{\circ} \mathrm{W}\end{array}$ & $\begin{array}{c}\text { Summer } \\
8 \text { August } 2009\end{array}$ & 12.4 & 390 & $\begin{array}{c}4.25 \times 10^{-2} \\
\text { (fix) }\end{array}$ & $\begin{array}{c}148.8 \\
(85-190)\end{array}$ & $\begin{array}{c}0.4018 \\
(0.3-0.8)\end{array}$ & $1.66 \times 10^{-5}$ \\
\hline $\begin{array}{l}\text { Transition } \\
44.3^{\circ} \mathrm{N}, 13.2^{\circ} \mathrm{W}\end{array}$ & $\begin{array}{c}\text { Spring } \\
20 \text { April } 2011\end{array}$ & 8.8 & 550 & $\begin{array}{c}4.25 \times 10^{-2} \\
\text { (fix) }\end{array}$ & $\begin{array}{c}186.7 \\
(85-250)\end{array}$ & $\begin{array}{c}0.034 \\
(0.007-0.5)\end{array}$ & $1.67 \times 10^{-5}$ \\
\hline
\end{tabular}
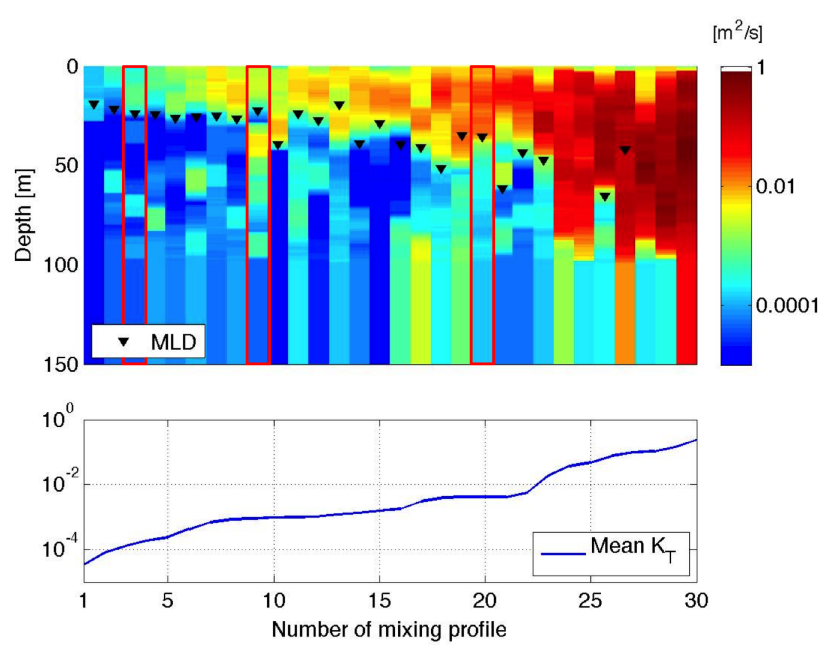

Figure 9. Measured vertical mixing profiles aligned according to the mean mixing strength with increasing strength along the $x$ axis as shown in the lower graph (logarithmic $y$ axis). The red boxes indicate the vertical mixing used for the model calibration at the southern, northern and transition station (left to right).

be seen already for the parameter calibration, the southern station is more responsive to changes than the other two stations. Even though the biological parameters of the southern and the transition station are very different, their results show more similarity than the results of the northern station. This indicates that the boundary conditions for the nutrients and the light have a very strong impact on the growth.

Overall, the phytoplankton concentration varies between very deep DCM states, DCM states close to the MLD, UCM states of different concentrations, and homogeneously mixed states. For the DCM states an increase of the mean mixing leads, with some exceptions, to a shift of the phytoplankton towards the surface. Results for the southern station show that the depth of the DCM is less controlled by the mean vertical mixing than by the strength of the mixing below the DCM. As a consequence the resupply of nutrients is limited and the nutrient concentrations of the deep DCM states are almost completely depleted (Fig. 11). Additionally, DCM states establish in depth sections of the water column

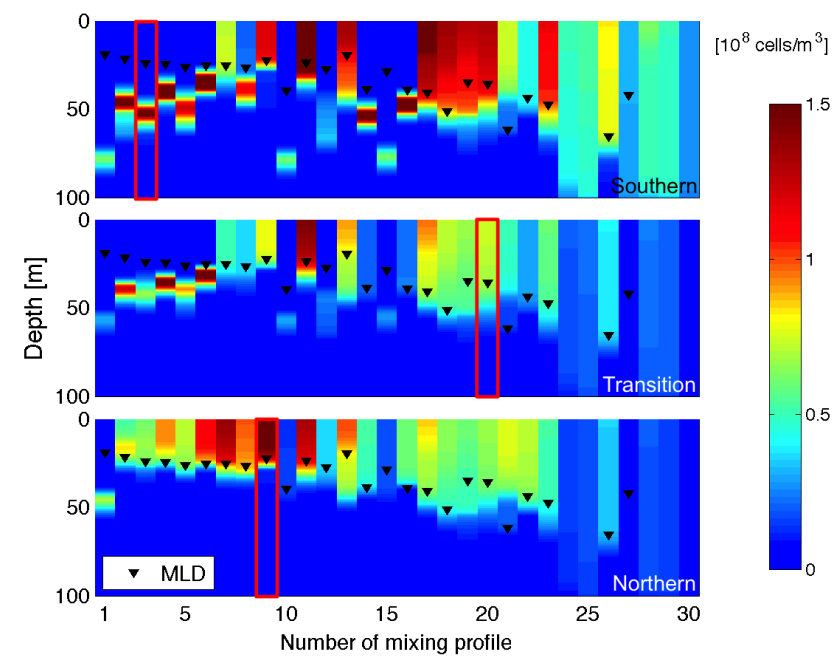

Figure 10. Phytoplankton concentration results of the sensitivity study based on the vertical mixing shown in Fig. 9 and the three reference stations: southern, transition and northern (top to bottom). The red boxes show the respective reference state.

in which the vertical mixing is low. Profile 16 has for example a high nutrient concentration below the DCM, which is even higher than at most of the UCM states. Still growth is restricted to a DCM and a possible explanation could be the very low vertical mixing between 40 and $70 \mathrm{~m}$ depth that leads to a bottleneck for the nutrient supply. At the southern station $N_{\mathrm{b}}$ is relatively low which intensifies this effect even more.

Comparing the DCM states of the southern station to those of the transition station, Fig. 10 shows that even though the DCMs of the transition station are closer to the surface and have more nutrients available, their concentration is lower than the one at the southern station under the same mixing conditions.

For the UCM states an increase of the mean mixing leads first to more nutrients in the ML and therefore a higher phytoplankton concentration. The change in the nutrient distribution can be seen in Fig. 11. The stronger the mixing gets the faster nutrients are resupplied and distributed over the water 
column. Another effect of the stronger mixing is the deepening of the ML. This leads to a lower phytoplankton concentration due to two reasons: the cells are diluted over a wider depth range and they are moved into deeper water, where the growth is limited by the lower light conditions. The latter has an especially strong impact when the vertical mixing becomes homogeneous and concentration decreases even more. Since growth rates are reduced by the lack of light, less nutrients are consumed and the nutrient concentration increases. In particular, the homogeneously mixed stations are characterised by surface nutrient concentrations close to the bottom value $N_{\mathrm{b}}$.

In general the vertical mixing below the ML is about one order higher for the UCM states than for the DCM states. The turning point from an enhancing to a reducing effect of the mixing is different for each reference state. At the northern station it appears already for low mixing leading to only one DCM state. At the transition station the window between the first UCM state and the highest surface concentration is rather small and concentrations decrease quickly as the mean vertical mixing increases further. Even though the calibration of the southern station makes it less likely to reach a UCM state, as soon as it is reached, growth is very strong leading to high surface concentrations.

Mixing profile 11 appears to have an ideal combination of nutrient supply and light availability for all reference stations. Other profiles with a similar MLD show a lower concentration while profiles with a deeper MLD spread the cells deeper. The latter is most significant for the phytoplankton concentrations based on homogeneous mixing. In particular, the last profile shows very little phytoplankton for all three calibrations.

\subsection{Bulk and surface sensitivity}

The results from the previous section indicate that the phytoplankton concentration at each of the reference stations is sensitive to the vertical mixing profile. The inhomogeneity of the vertical mixing profiles complicates the identification of the main controlling processes. Therefore different characteristics of the mixing are analysed for their correlation to the phytoplankton growth.

As mentioned above, the DCM states appear to be more sensitive to the mixing below the DCM. In Fig. 12a the depth of the DCM is therefore given as function of the mean vertical mixing below the DCM (and not over the whole profile as above). The data of the southern station and the transition station show an exponential decrease of the depth of the DCM with the increasing mixing, while the DCMs at the transition station are generally shallower. The data point for the northern station fits into this behaviour, but is not sufficient for further analysis. The outlier of the southern station at the high end of the mean mixing corresponds to profile 16 , whose special behaviour was discussed in the previous section.

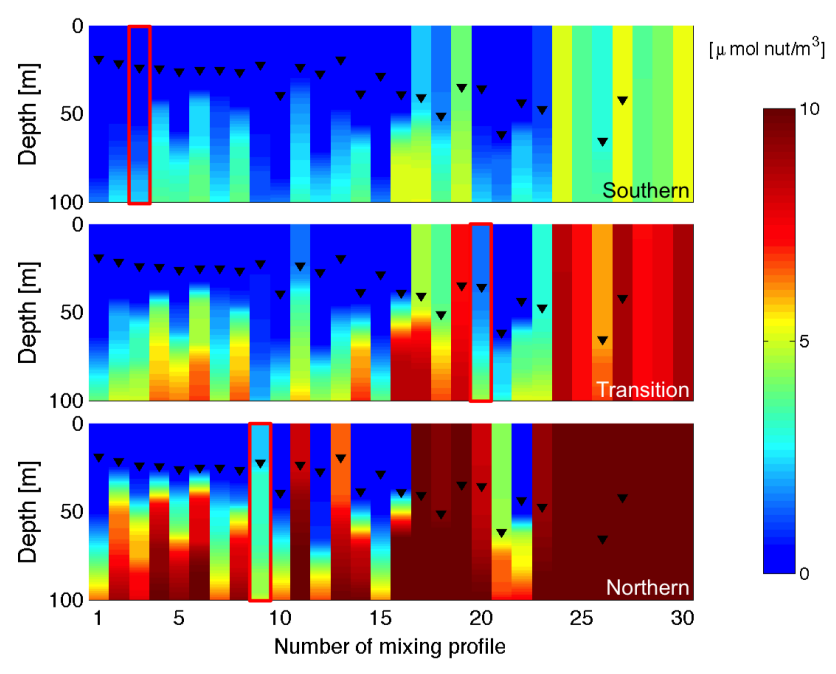

Figure 11. Nutrient concentration results of the sensitivity study based on the vertical mixing shown in Fig. 9 and the three reference stations: southern, transition and northern (top to bottom). The red boxes show the respective reference state.

To compare the phytoplankton distributions of the UCM or homogeneous states, the mean surface phytoplankton concentration over the upper $20 \mathrm{~m}$ is calculated, here indicated by $P_{\mathrm{s}}$. Values of $P_{\mathrm{s}}$ computed from the results in Fig. 10 lie in the range of $0.5-23.2 \times 10^{8}$ cells m$^{-3}$ for the stratified vertical mixing profiles and between 0.3 and $5.8 \times 10^{8}$ cells m$^{-3}$ for the homogeneously mixed profiles (Fig. 12b). The strong vertical mixing at profile 30 leads to the extinction of phytoplankton at the transition station and the northern station. Overall, the behaviour of $P_{\mathrm{s}}$ as a function of the mean vertical mixing is very similar at these two reference stations.

The sensitivity of the southern station can also be seen in the high values of $P_{\mathrm{s}}$. Phytoplankton profiles based on profiles with strong vertical mixing (e.g. the homogeneously mixed profiles) lead to larger $P_{\mathrm{s}}$ values at the southern station than those at the other two reference stations. The reason for the enhanced growth is the combination of the high $I_{\text {in }}$ and the low $H_{I}$ at the southern station.

The growth function in Eq. (4) divides the water column into a light-limited and a nutrient-limited growth regime. The transition between the two coincides with the position of the nutricline, which is defined as the depth of the largest gradient in the vertical nutrient concentration. In Fig. 13a, the total biomass is plotted as a function of the depth of the nutricline. Model states which are not limited by nutrients have no nutricline and are found along the $y$ axis. Though data points are fairly spread, their distribution indicates that a shallower nutricline leads to an increase of the total biomass.

These results suggest that the vertical mixing in combination with the boundary condition $N_{\mathrm{b}}$ play a very important role in the supply of nutrients to the euphotic layer. Still, their result does not show a clear trend nor does the method take 


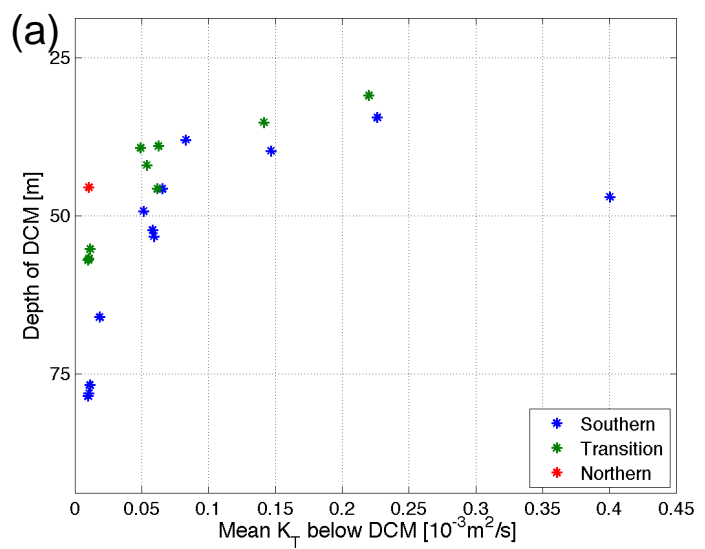

(b)

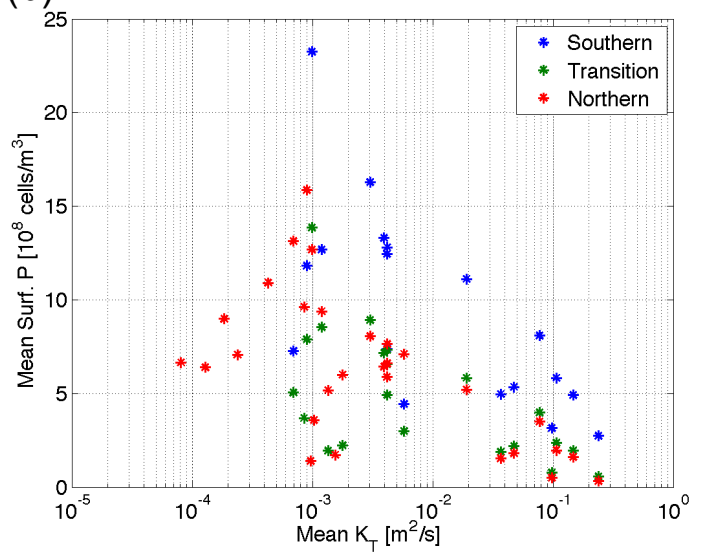

Figure 12. Comparison of the model results for the three reference stations. (a) Depth of the DCM as a function of the mean vertical mixing below the DCM. (b) Mean surface phytoplankton concentration for all UCM and homogeneously mixed states.

the vertical characteristics of the mixing into account. To obtain a more quantitative measure of the effect of the vertical mixing on the vertical distribution of the nutrient concentration, a (dimensionless) relative nutrient flux $\rho_{N}^{i}$ is defined as

$$
\begin{aligned}
\rho_{\mathrm{N}}^{i}= & \frac{-K^{i}(z) \frac{\partial N^{i}}{\partial z}}{\overline{\left[-K(z) \frac{\partial N}{\partial z}\right]_{\mathrm{ref}}}} \\
\approx & \frac{\sum_{j=0}^{J-1}\left[K_{T}^{i}\left(z_{j}\right)\left(N^{i}\left(z_{j+1}\right)-N^{i}\left(z_{j}\right)\right)\right]}{\sum_{j=0}^{J-1}\left[K_{T}\left(z_{j}\right)\left(N\left(z_{j+1}\right)-N\left(z_{j}\right)\right)\right]_{\mathrm{ref}}},
\end{aligned}
$$

where $i$ is the profile number, $J$ is the number of grid points in the vertical and the bar indicates vertical averaging. The denominator normalises the flux with the nutrient flux of the correspondent reference station (e.g. at the reference stations $\rho_{N}^{\text {ref }}$ is 1). It follows that values of $\rho_{N}^{i}$ measure the influence of the change in the vertical mixing compared to the reference state.
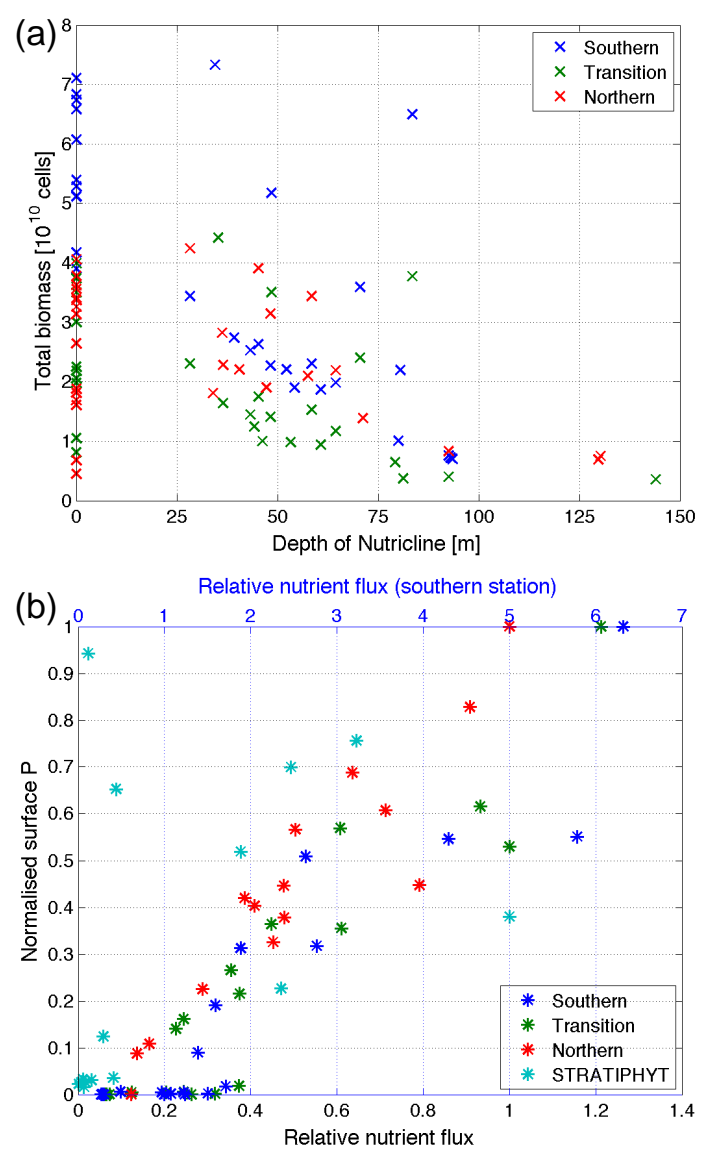

Figure 13. (a) The total biomass integrated over the water column as a function of the depth of the nutricline. (b) Normalised surface phytoplankton concentration vs. the relative nutrient flux for the three reference stations and the measured STRATIPHYT data. For the modelled data only the nutrient-limited states are taken into account.

In Fig. 13b the normalised values of $P_{\mathrm{S}}$ are plotted against $\rho_{N}^{i}$. Every $P_{\mathrm{S}}$ is normalised by the maximum value of each reference station to facilitate the comparison between reference stations. (The reference nutrient flux at the southern station is very low, which leads to high values of $\rho_{N}^{i}$ and hence a different scale is used.) In all three cases $P_{\mathrm{s}}$ increases with the increasing nutrient flux. The relative nutrient flux shows a strong correlation for all reference stations. The STRATIPHYT data (taking the measured nutrient at the transition station as reference) shows a wider spread but generally a similar correlation. In contrast to the other measures above, $\rho_{N}^{i}$ incorporates the vertical characteristics of the mixing as well as the nutrient concentration and is therefore capable of giving a more integrated picture of the growth environment. 


\section{Summary and discussion}

In this work, we used in situ measurements of the STRATIPHYT project to calibrate three sets of model parameters for a one-dimensional phytoplankton model. Subsequently, the three model calibrations were used to study the sensitivity of the phytoplankton distribution to measured vertical mixing. A discussion of the calibration of the parameters in the model was given in Sect. 4.3. We are confident that the three parameters are a good choice to represent characteristic phytoplankton growth with the model.

When compared to in situ as well as to the ocean colour data, the phytoplankton concentration at the surface for the deep DCM states is up to two orders of magnitude too low. However, the model results for shallow DCM states and for UCM states are of the same order as the measurements. Comparisons to in situ measurements have shown that the OCM3 algorithm (used for the satellite data) underestimates Chl $a$ concentrations below $1 \mathrm{mg} \mathrm{m}^{-3}$, and overestimates them at larger values. In the latter case this would mean that the model might perform even better at high concentrations than the comparison would suggest. On the other hand the performance at low concentration might be even poorer (see Martin, 2004, and http://oceancolor.gsfc.nasa.gov/ for more details).

In contrast to previous sensitivity studies, the model is forced by measured profiles of vertical mixing as shown in Fig. 9. To compare the results to previous work, correlations with general measures such as the mean vertical mixing strength are analysed. For mixing profiles with a weak mean mixing, the low value of $N_{\mathrm{b}}$ combined with the relative high $H_{N}$ leads mainly to DCM states at the southern station. At the northern station, the high $N_{\mathrm{b}}$ leads predominantly to UCM states. Independent of the distinctive values of $H_{N}$ and $\varepsilon$ at the transition station, the model results lie in between those of the other two stations. Mixing profiles which lead to a DCM at the southern station result either in a shallower DCM for the transition station (see Fig. 12a) or even a UCM as for the northern station. Also the nutrient concentration in Fig. 11 underlines the intermediate character of the transition station. This suggests that the boundary conditions for the light and the nutrients have a stronger impact on the model results than the calibration of the model parameters. It also shows that changes of the mean mixing lead to changes in the equilibrium state, as can be seen in Fig. 12 and was shown for example by Ryabov et al. (2010).
Results also show that the phytoplankton distribution based on strong mean mixing are less diverse among the three reference stations and almost all show a UCM state. The difference lies in the concentration of the UCM: at the southern station the low $H_{I}$ paired with a high $I_{\text {in }}$ and the effective resupply of nutrients to the ML makes the plankton grow stronger than at the other two stations. This result is also obtained from Fig. 12b where a clear offset between the southern data and the more northern data can be seen, especially for high vertical mixing. Huisman and Weissing (1994) find similar conclusions and discuss the underlying processes in more detail.

For weaker mean mixing the model results show the importance of the nutrient supply to the euphotic layer. Nutrient-limited states show an increase in total biomass with the shallowing of the nutricline (Fig. 13a). Based on this result, the relative nutrient flux was defined as a new measure that incorporates both the vertical structure of the mixing and the distribution of nutrients. With this measure changes of surface phytoplankton concentration can be directly correlated to the strength of the vertical mixing and its impact on the nutrient supply. Results in Fig. 13b show a stronger correlation than previous results, which were based on the mean vertical mixing. This implies that information gets lost when the vertical structure of the mixing is generalised to a mean value and most importantly that the growth is sensible to small-scale variations of the vertical mixing.

In summary, the usage of measured vertical mixing profiles instead of idealised mixing schemes leads generally to similar results as previous studies. Including the characteristics of the vertical structure in the analysis showed that smallscale variations in the vertical mixing and the nutrient distribution have a strong impact on the surface phytoplankton concentration. This strong correlation of $\rho_{N}$ to the surface phytoplankton concentration suggests that data-assimilation techniques may be useful to constrain properties of turbulent vertical mixing with the help of surface $\mathrm{Chl} a$ concentrations. However, the results also indicate that this will be challenging as the surface concentration in the case of the modelled DCM is in most cases underestimated and has also a strong variability. Further research on the impact of the temporal change in the vertical mixing and the boundary conditions will show to what extent the surface $\mathrm{Chl} a$ concentration can be used to remotely determine properties of the small-scale structure of the upper ocean. 


\section{Appendix A: Calculation of $\boldsymbol{k}$ and $\boldsymbol{K}_{\mathrm{bg}}$}

Figure A1 shows the vertical profiles of fluorescence, corrected irradiance and the surface irradiance as one example of the total of 100 CTD measurements used for the analysis. The corrected irradiance is the percentage of the instantaneous surface light intensity measured at depth. Variations of the surface irradiance on short timescales (e.g. change in cloud coverage) as well as long timescales (e.g. diurnal changes) do therefore not affect the analysis of the transmittance of the water. The $x$ axis goes from 0 (surface) to $250 \mathrm{~m}$ depth. At depths below $140 \mathrm{~m}$ the fluorescence signal shows slightly varying values above zero. These appear due to measurement artefacts, the so-called dark current, and Chl $a$ concentrations can be assumed to be very low or even zero here.

In Fig. A1 the blue interval limited by $z_{1}$ and $z_{2}$ defines the phytoplankton-free depth section. The integral over $P(z)$ in the exponent of Eq. (5) remains constant over this interval since there is no additional phytoplankton found below $z_{1}$. This constant term is used to eliminate the $k$ dependency by combining Eq. (5) at depth $z_{2}$ with the same equation at depth $z_{1}$. Rearranging leads to

$K_{\mathrm{bg}}=\frac{\log \left(\frac{I\left(z_{1}\right)}{I_{\text {in }}\left(z_{1}\right)}\right)-\log \left(\frac{I\left(z_{2}\right)}{I_{\text {in }}\left(z_{2}\right)}\right)}{z_{2}-z_{1}}$

from which $K_{\mathrm{bg}}$ is determined for the given irradiance profiles.

As soon as a value for $K_{\mathrm{bg}}$ is found, the effect of the phytoplankton distribution within the water column can be determined. To do so, another section $\left[z_{3}, z_{4}\right]$, which contains a high concentration of phytoplankton cells, is defined. Here we choose the depths in which the phytoplankton concentration reaches half of its maximum value, above and below the depth of the maximum phytoplankton concentration. In Fig. A1 this section is marked by the green shaded area. We first write Eq. (5) for both depths $z_{3}$ and $z_{4}$ and take the logarithm of both equations (which linearises the dependency on $k$ ). Substituting the two resulting equations leads to

$$
\begin{aligned}
\log \left(\frac{I\left(z_{3}\right)}{I_{\text {in }}\left(z_{3}\right)}\right)-\log \left(\frac{I\left(z_{4}\right)}{I_{\text {in }}\left(z_{4}\right)}\right) \\
=-K_{\mathrm{bg}}\left(z_{3}-z_{4}\right)-\left(\int_{0}^{z_{3}} k P(\zeta) \mathrm{d} \zeta-\int_{0}^{z_{4}} k P(\zeta) \mathrm{d} \zeta\right) .
\end{aligned}
$$

The term in parentheses in the right-hand side of Eq. (A2) can be combined into one integral. To calculate the integral numerically, we use the trapezoidal rule given by

$$
\begin{aligned}
P_{\mathrm{PEAK}} & =\int_{z_{3}}^{z_{4}} P(\zeta) \mathrm{d} \zeta \\
& \approx 0.5\left(P\left(z_{3}\right)+2 \sum_{n=z_{3}+1}^{z_{4}-1} P(n)+P\left(z_{4}\right)\right)
\end{aligned}
$$

which gives the total amount of phytoplankton $P_{\text {PEAK }}$ within the section $\left[z_{3}, z_{4}\right]$. Rearranging Eq. (A2) gives an expression for the absorption coefficient of phytoplankton $k$ as

$$
\begin{aligned}
& k= \\
& \frac{1}{P_{\text {PEAK }}}\left(K_{\text {bg }}\left(z_{3}-z_{4}\right)+\log \left(\frac{I\left(z_{3}\right)}{I_{\text {in }}\left(z_{3}\right)}\right)-\log \left(\frac{I\left(z_{4}\right)}{I_{\text {in }}\left(z_{4}\right)}\right)\right) .
\end{aligned}
$$




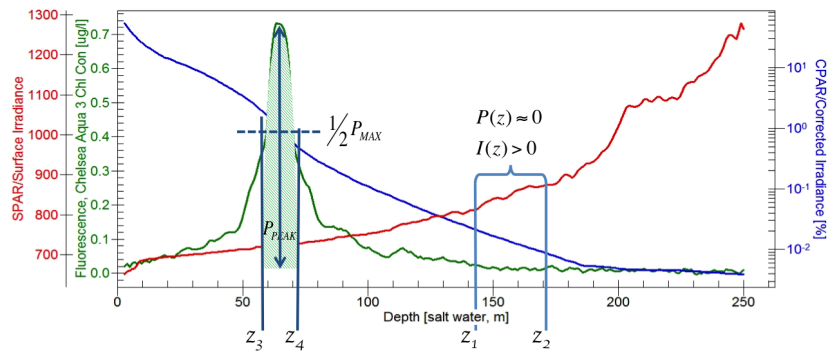

Figure A1. CTD data at Station $7\left(36.3^{\circ} \mathrm{N} 13.5^{\circ} \mathrm{W}\right) 21$ July 2009, 11 a.m. Depth profile of the Chl $a$ concentration (green line), depth profile of the corrected irradiance (blue line), and surface irradiance at the time of the measurement at depth (red line). The light blue lines indicate the depth section used to extract $K_{\mathrm{bg}}$. The green-shaded area symbolises the phytoplankton concentration which is used to determine $k$.
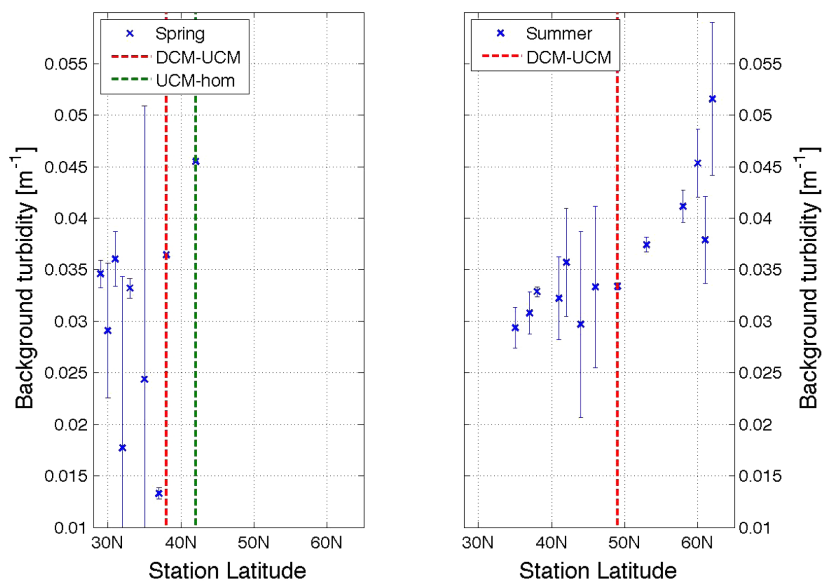

Figure A2. Mean $K_{\mathrm{bg}}$ per station based on irradiance profiles measured in spring (left) and summer (right). Error bars give the standard deviation per station. The vertical dashed lines define the latitude at which the system changes its state: red is the transition from a DCM to a UCM state and green from a UCM to a homogeneously mixed state (from south to north).
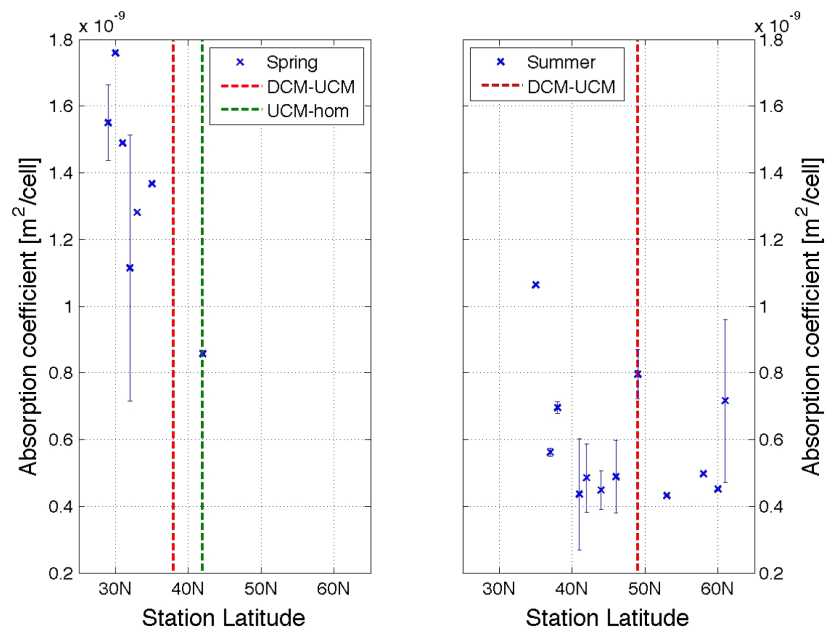

Figure A3. Mean $k$ per station based on irradiance profiles and Chl $a$ concentration profiles measured in spring (left) and summer (right). See caption of Fig. A2 for further description. 
Acknowledgements. Special thanks go to Elena Jurado for her help with the STRATIPHYT data, to Corina Brussaard, the chief scientist of the two STRATIPHYT cruises, and the crew of the R/V Pelagia. We also thank Roeland van de Vijsel for his work on the satellite data. This work was funded by the NSO User Support Programme under Grant ALW-GO-AO/11-08 through the COLOURMIX project with financial support of the Netherlands Organization for Scientific Research (NWO).

Edited by: O. Zielinski

\section{References}

Antoine, D., Morel, A., Gordon, H., Banzon, V., and Evans, R.: Bridging ocean color observations of the 1980s and 2000s in search of long-term trends, J. Geophys. Res., 110, C06009, doi:10.1029/2004JC002620, 2005.

Beckmann, A. and Hense, I.: Beneath the surface: Characteristics of oceanic ecosystems under weak mixing conditions - A theoretical investigation, Prog. Oceanogr., 75, 771-796, doi:10.1016/j.pocean.2007.09.002, 2007.

Behrenfeld, M. J.: Abandoning Sverdrup's Critical Depth Hypothesis on phytoplankton blooms, Ecology, 91, 977-989, doi:10.1890/09-1207.1, 2010.

Behrenfeld, M. J., O’Malley, R. T., Siegel, D. A., McClain, C. R., Sarmiento, J. L., Feldman, G. C., Milligan, A. J., Falkowski, P. G., Letelier, R. M., and Boss, E. S.: Climate-driven trends in contemporary ocean productivity, Nature, 444, 752-755, doi:10.1038/nature05317, 2006.

Boyce, D. G., Lewis, M. R., and Worm, B.: Global phytoplankton decline over the past century, Nature, 466, 591-596, doi:10.1038/nature09268, 2010.

Brea, S., Alvarez-Salgado, X., Alvarez, M., Perez, F., Memery, L., Mercier, H., and Messias, M.: Nutrient mineralization rates and ratios in the eastern South Atlantic, J. Geophys. Res.-Oceans, 109, C05030, doi:10.1029/2003JC002051, 2004.

Doney, S. C.: Oceanography: Plankton in a warmer world, Nature, 444, 695-696, doi:10.1038/444695a, 2006.

Evans, M. R., Grimm, V., Johst, K., Knuuttila, T., de Langhe, R., Lessells, C. M., Merz, M., O’Malley, M. A., Orzack, S. H., Weisberg, M., Wilkinson, D. J., Wolkenhauer, O., and Benton, T. G.: Do simple models lead to generality in ecology?, Trends Ecol. Evol., 28, 578-583, doi:10.1016/j.tree.2013.05.022, 2013.

Falkowski, P. and Raven, J.: Aquatic photosynthesis, Princeton University Press: Princeton, 2nd Edn., 2007.

Fiechter, J.: Assessing marine ecosystem model properties from ensemble calculations, Ecol. Modell., 242, 164-179, doi:10.1016/j.ecolmodel.2012.05.016, 2012.

Huisman, J. and Sommeijer, B.: Population dynamics of sinking phytoplankton in light-limited environments: simulation techniques and critical parameters, J. Sea Res., 48, 83-96, doi:10.1016/S1385-1101(02)00137-5, 2002.

Huisman, J. and Weissing, F. J.: Light-limited growth and competition for light in well-mixed aquatic environments - an elementary model, Ecology, 75, 507-520, doi:10.2307/1939554, 1994.

Huisman, J., Thi, N., Karl, D., and Sommeijer, B.: Reduced mixing generates oscillations and chaos in the oceanic deep chlorophyll maximum, Nature, 439, 322-325, doi:10.1038/nature04245, 2006.

Johnk, K. D., Huisman, J., Sharples, J., Sommeijer, B., Visser, P. M., and Stroom, J. M.: Summer heatwaves promote blooms of harmful cyanobacteria, Glob. Change Biol., 14, 495-512, doi:10.1111/j.1365-2486.2007.01510.x, 2008.

Jurado, E., Dijkstra, H. A., and van der Woerd, H. J.: Microstructure observations during the spring 2011 STRATIPHYT-II cruise in the northeast Atlantic, Ocean Sci., 8, 945-957, doi:10.5194/os8-945-2012, 2012a.

Jurado, E., van der Woerd, H. J., and Dijkstra, H. A.: Microstructure measurements along a quasi-meridional transect in the northeastern Atlantic Ocean, J. Geophys. Res.-Oceans, 117, C04016, doi:10.1029/2011JC007137, 2012b.

Kirk, J.: Light and Photosynthesis in Aquatic Ecosystems, Cambridge University Press, 2011.

Klausmeier, C. and Litchman, E.: Algal games: The vertical distribution of phytoplankton in poorly mixed water columns, Limnol. Oceanogr., 46, 1998-2007, 2001.

Levitus, S., Antonov, J., Boyer, T., and Stephens, C.: Warming of the world ocean, Science, 287, 2225-2229, doi:10.1126/science.287.5461.2225, 2000.

Liccardo, A., Fierro, A., Iudicone, D., Bouruet-Aubertot, P., and Dubroca, L.: Response of the deep chlorophyll maximum to fluctuations in vertical mixing intensity, Prog. Oceanogr., 109, 3346, doi:10.1016/j.pocean.2012.09.004, 2013.

Losa, S. N., Kivman, G. A., and Ryabchenko, V. A.: Weak constraint parameter estimation for a simple ocean ecosystem model: what can we learn about the model and data?, J. Marine Syst., 45, 1-20, doi:10.1016/j.jmarsys.2003.08.005, 2004.

Lozier, M. S., Dave, A. C., Palter, J. B., Gerber, L. M., and Barber, R. T.: On the relationship between stratification and primary productivity in the North Atlantic, Geophys. Res. Lett., 38, L18609, doi:10.1029/2011GL049414, 2011.

Mahadevan, A., D’Asaro, E., Lee, C., and Perry, M. J.: EddyDriven Stratification Initiates North Atlantic Spring Phytoplankton Blooms, Science, 337, 54-58, doi:10.1126/science.1218740, 2012.

Martin, S.: An introduction to Ocean Remote Sensing, ISBN 9780-521-80280-2, Cambridge University Press, 2004.

Martinez, E., Antoine, D., D’Ortenzio, F., and Gentili, B.: ClimateDriven Basin-Scale Decadal Oscillations of Oceanic Phytoplankton, Science, 326, 1253-1256, doi:10.1126/science.1177012, 2009.

McGillicuddy, D. J., Anderson, L. A., Bates, N. R., Bibby, T., Buesseler, K. O., Carlson, C. A., Davis, C. S., Ewart, C., Falkowski, P. G., Goldthwait, S. A., Hansell, D. A., Jenkins, W. J., Johnson, R., Kosnyrev, V. K., Ledwell, J. R., Li, Q. P., Siegel, D. A., and Steinberg, D. K.: Eddy/Wind Interactions Stimulate Extraordinary Mid-Ocean Plankton Blooms, Science, 316, 1021-1026, doi:10.1126/science.1136256, 2007.

Mellard, J. P., Yoshiyama, K., Litchman, E., and Klausmeier, C. A.: The vertical distribution of phytoplankton in stratified water columns, J. Theor. Biol., 269, 16-30, doi:10.1016/j.jtbi.2010.09.041, 2011.

Mobley, C. D.: Light and Water: Radiative Transfer in Natural Waters, Academic Press, San Diego, California, 1994. 
Morel, A., Gentili, B., Claustre, H., Babin, M., Bricaud, A., Ras, J., and Tièche, F.: Optical properties of the "clearest" natural waters, Limnol. Oceanogr., 52, 217-229, 2007.

Omta, A. W., Llido, J., Garcon, V., Kooijman, S. A. L. M., and Dijkstra, H. A.: The interpretation of satellite chlorophyll observations: The case of the Mozambique Channel, Deep Sea Res.-Pt. I, 56, 974-988, doi:10.1016/j.dsr.2009.01.011, 2009.

O'Reilly, J., Maritorena, S., O’Brien, M., Siegel, D., Toole, D., Menzies, D., Smith, R., Mueller, J., Mitchell, B., Kahru, M., Chavez, F., Strutton, P., Cota, G., Hooker, S., McClain, C. R., Carder, K., Müller-Karger, F., Harding, L., Magnuson, A., Phinney, D., Moore, G., Aiken, J., Arrigo, K., Letelier, R. M., and Culver, M.: SeaWiFS Postlaunch Calibration and Validation Analyses, Part 3, Vol. 11, Nasa Tech. Memo., Nasa Goddard Space Flight Center, 2000.

Osborn, T.: Oceanic fine structure, Geophys. Astro. Fluid, 3, 321345, 1972.

Peters, F., Arin, L., Marrasé, C., Berdalet, E., and Sala, M.: Effects of small-scale turbulence on the growth of two diatoms of different size in a phosphorus-limited medium, J. Marine Syst., 61, 134-148, doi:10.1016/j.jmarsys.2005.11.012, 2006.

Roget, E., Lozovatsky, I., Sanchez, X., and Figueroa, M.: Microstructure measurements in natural waters: Methodology and applications, Prog. Oceanogr., 70, 126-148, doi:10.1016/j.pocean.2006.07.003, 2006.

Ryabov, A., Rudolf, L., and Blasius, B.: Vertical distribution and composition of phytoplankton under the influence of an upper mixed layer, J. Theor. Biol., 263, 120-133, doi:10.1016/j.jtbi.2009.10.034, 2010.

Siegel, D. A., Maritorena, S., Nelson, N. B., and Behrenfeld, M. J.: Independence and interdependencies among global ocean color properties: Reassessing the bio-optical assumption, J. Geophys. Res.-Oceans, 110, C07011, doi:10.1029/2004JC002527, 2005.
Suggett, D. J., Prasil, O., and Borwitzka, M. A.: Chlorophyll $a$ Fluorescence in Aquatic Sciences: Methods and Applications, Springer, The Netherlands, 2011.

Sverdrup, H. U.: On Conditions for the Vernal Blooming of Phytoplankton, Journal du Conseil, 18, 287-295, doi:10.1093/icesjms/18.3.287, 1953.

Thi, N. P., Huisman, J., and Sommeijer, B.: Simulation of threedimensional phytoplankton dynamics: competition in lightlimited environments, J. Comput. Appl. Math., 174, 57-77, doi:10.1016/j.cam.2004.03.023, 2005.

Valenti, D., Denaro, G., La Cognata, A., Spagnolo, B., Bonanno, A., Basilone, G., Mazzola, S., Zgozi, S., and Aronica, S.: Picophytoplankton dynamics in noisy marine environment, Acta Phys. Pol. B, 43, 1227-1240, doi:10.5506/APhysPolB.43.1227, 24th Marian Smoluchowski Symposium on Statistical Physics, Zakopane, Poland, 17-22 September 2011, 2012.

van de Poll, W. H., Kulk, G., Timmermans, K. R., Brussaard, C. P. D., van der Woerd, H. J., Kehoe, M. J., Mojica, K. D. A., Visser, R. J. W., Rozema, P. D., and Buma, A. G. J.: Phytoplankton chlorophyll a biomass, composition, and productivity along a temperature and stratification gradient in the northeast Atlantic Ocean, Biogeosciences, 10, 4227-4240, doi:10.5194/bg10-4227-2013, 2013.

Wernand, M. R., van der Woerd, H. J., and Gieskes, W. W. C.: Trends in Ocean Colour and Chlorophyll Concentration from 1889 to 2000, Worldwide, Plos One, 8, e63766, doi:10.1371/journal.pone.0063766, 2013. 